\title{
Energetics of the Tropical Atlantic Zonal Mode
}

\author{
N. J. BuRls AND C. J. C. REASON \\ University of Cape Town, Cape Town, South Africa \\ P. PENVEN \\ Laboratoire de Physique des Oceans (UMR 6523 CNRS, IFREMER, IRD, UBO), LMI ICEMASA, Plouzane, \\ France, and University of Cape Town, Cape Town, South Africa \\ S. G. PHILANDER \\ Princeton University, Princeton, New Jersey
}

(Manuscript received 5 October 2011, in final form 5 April 2012)

\begin{abstract}
Sea surface temperature in the central-eastern equatorial Atlantic has a seasonal cycle far bigger than that of the Pacific, but interannual anomalies smaller than those of the Pacific. Given the amplitude of seasonal SST variability, one wonders whether the seasonal cycle in the Atlantic is so dominant that it is able to strongly influence the evolution of its interannual variability. In this study, interannual upper-ocean variability within the tropical Atlantic is viewed from an energetics perspective, and the role of ocean dynamics, in particular the role of ocean memory, within zonal mode events is investigated. Unlike in the Pacific where seasonal and interannual variability involve distinctly different processes, the results suggest that the latter is a modulation of the former in the Atlantic, whose seasonal cycle has similarities with El Niño and La Niña in the Pacific. The ocean memory mechanism associated with the zonal mode appears to operate on much shorter time scales than that associated with the El Niño-Southern Oscillation, largely being associated with interannual modulations of a seasonally active delayed negative feedback response. Differences between the El Niño-Southern Oscillation and the zonal mode can then be accounted for in terms of these distinctions. Anomalous wind power over the tropical Atlantic is shown to be a potential predictor for zonal mode events. However, because zonal mode events are due to a modulation of seasonally active coupled processes, and not independent processes operating on interannual time scales as seen in the Pacific, the lead time of this potential predictability is limited.
\end{abstract}

\section{Introduction}

In the eastern tropical Pacific, large changes in sea surface temperature (SST) are highly correlated with changes in the depth of the thermocline on interannual but not on seasonal time scales. The ocean-atmosphere interactions that determine the oscillations between $\mathrm{El}$ Niño and La Niña are entirely different from those that influence the seasonal cycle (Chang and Philander 1994). In the Atlantic, on the other hand, the seasonal cycle of SST involves vertical movements of the thermocline (Merle 1980; Vauclair and du Penhoat 2001; Xie

Corresponding author address: N. J. Burls, Department of Oceanography, University of Cape Town, Private Bag X3, Rondebosch, Cape Town 7701, South Africa.

E-mail: nats.burls@gmail.com and Carton 2004; Schouten et al. 2005; Burls et al. 2011). While seasonal SST fluctuations are large, interannual variations in the Atlantic are modest in amplitude, and have a complex spatial structure that is usually described in terms of two modes: the "meridional mode" and the "zonal mode" (Chang et al. 2006a). The zonal mode is equatorially focused and attributed to dynamic air-sea interactions, while the meridional mode is associated with off-equatorial tropical SST variability and is attributed to thermodynamic air-sea interactions (Chang et al. 2006a). These modes of interannual tropical Atlantic climate variability are associated with fluctuations in precipitation over surrounding countries (Xie and Carton 2004; Kushnir et al. 2006); therefore, an improved understanding of the processes behind them and their predictability is a matter of socioeconomic importance. 
Focusing on the zonal mode as ocean dynamics, a possible source of predictability, are credited with its development, the zonal mode is often referred to as the "Atlantic Niño" mode because its spatial signature resembles the Pacific El Niño-Southern Oscillation (ENSO) (Merle 1980; Hisard 1980; Zebiak 1993; Carton and Huang 1994; Ruiz-Barradas et al. 2000). Like ENSO, it displays a SST-wind relationship whereby a decrease (increase) in the equatorial trades is associated with positive (negative) SST anomalies in the eastern equatorial Atlantic (Merle 1980; Servain et al. 1982; Zebiak 1993; Ruiz-Barradas et al. 2000; Kushnir et al. 2006). Analogous to the Pacific, the Bjerknes feedback mechanism (Bjerknes 1969) is believed to be behind the growth of the zonal mode events (Carton and Huang 1994; Keenlyside and Latif 2007; Chang et al. 2000).

While the spatial signature of SST and wind variations associated with the equatorial zonal mode clearly resembles that of ENSO, the observational analysis of Zebiak (1993) also revealed several important differences between the nature of the zonal mode and ENSO. The most apparent is that the anomalous wind-SST relationship observed in the Atlantic is weaker and less consistent (Zebiak 1993; Ruiz-Barradas et al. 2000; Keenlyside and Latif 2007). Furthermore, the relationship between interannual SST anomalies and thermocline depth anomalies in the equatorial Pacific is far more robust than in the equatorial Atlantic (Zebiak 1993; Vauclair and du Penhoat 2001; Keenlyside and Latif 2007). Not all interannual SST anomalies in the eastern-central equatorial Atlantic are associated with thermocline depth anomalies (Carton and Huang 1994). While some warm SST events in the eastern tropical Atlantic have been attributed to anomalous vertical temperature gradients due to a change in the east-west slope of the thermocline, others have not exhibited this El Niño-like characteristic.

Therefore, while ENSO accounts for the preponderance of interannual SST variability in the Pacific, the zonal mode explains a smaller percentage of the observed variability in the Atlantic. This difference between the zonal mode and ENSO has been attributed to a larger contribution from external forcing (Chang et al. 2000) and other local air-sea interactions in the tropical Atlantic (e.g., local thermodynamic feedbacks associated with the meridional mode or the local Ekman feedback, Zebiak 1993; Chang et al. 2006a).

Another notable difference between the nature of the zonal mode and ENSO is that the Atlantic has more high frequency variability (shorter events) with larger contributions at seasonal time scales (Zebiak 1993; Latif and Grötzner 2000). With no significant spectral peak at interannual time scales, spectral characteristics are hardly discernible from red noise. The zonal mode is therefore described as stable (damped) and noise driven (Latif and Barnett 1995; Nobre et al. 2003; Illig and Dewitte 2006; Kushnir et al. 2006; Keenlyside and Latif 2007).

Furthermore, the zonal mode and ENSO exhibit a very different relationship with the seasonal cycle: SST anomalies associated with ENSO events peak in boreal winter, while those associated with the zonal mode peak in boreal summer (Zebiak 1993; Latif and Grötzner 2000; Keenlyside and Latif 2007).

This added complexity in the Atlantic has made diagnosing the role of ocean memory within zonal mode events somewhat more difficult than in the case of the Pacific. Although it is of equal importance as the Bjerknes mechanism, the delayed negative ocean feedback has received much less attention and its role within zonal mode events is poorly understood (Chang et al. 2006a; Keenlyside and Latif 2007).

Given the amplitude of seasonal SST variability in the central-eastern equatorial Atlantic, one wonders whether the seasonal cycle in the Atlantic is so dominant that it is able to strongly influence the evolution of its interannual variability? As seen in the atmosphere (Hastenrath 1984), are the physical ocean processes involved in interannual zonal-mode SST variability the same, except for a modulation in either phase or amplitude, or are the processes different from those of the seasonal cycle? What is the role of ocean memory within central-eastern equatorial Atlantic SST variability? The analysis carried out within this paper aims to address these questions.

Results obtained in the companion paper Burls et al. (2011) suggest that remotely forced thermocline depth changes play a crucial role in driving seasonal centraleastern basin SST changes, a process that only plays a significant role interannually in the Pacific. As a result, large seasonal fluctuations in the available potential energy (APE) of the upper equatorial Atlantic, which track the horizontal redistribution of warm surface waters in response to the changes in wind forcing, are strongly anticorrelated with seasonal central-eastern basin SST changes. Like SST, the seasonal cycle dominates APE variability. Furthermore, the relationship between seasonal SST, APE, and zonal wind stress changes in the Atlantic supports the notion that the greater and steeper seasonal decrease in SST associated with the development of the cold tongue in the Atlantic in comparison to the Pacific is due to the fact that the seasonally excited growth of asymmetric conditions about the equator is accompanied by a seasonally excited Bjerknes feedback as the thermocline shoals seasonally in the Atlantic (Burls et al. 2011). This seasonally excited Bjerknes 
feedback is then damped between August and October by a delayed, negative, ocean memory feedback mechanism (Burls et al. 2011). In the Pacific, interannual APE anomalies are grown by the Bjerknes feedback mechanism until the delayed response of the ocean affects the ability of the wind to do work on the ocean (Goddard and Philander 2000). The results of the energetics analysis presented within Burls et al. indicates that a similar process, referred to as a seasonally excited thermocline mode, is active in the Atlantic between April and September at which point seasonal forcing regains control.

The difference in the time scale of the largest SST fluctuations between the Pacific and Atlantic basins is therefore attributed to the fact that in the Pacific the Bjerknes feedback and its associated delayed, negative feedback mechanism operate on interannual time scales whereas in the Atlantic, they operates seasonally (Burls et al. 2011). Can interannual SST variability associated with the zonal mode therefore be explained in terms of a modulation of this seasonally active thermocline mode?

As demonstrated by previous studies in the Pacific (Goddard and Philander 2000; Fedorov et al. 2003; Fedorov 2007), an assessment of the energetics of interannual equatorial ocean variability can shed light on the mechanisms governing ocean-atmosphere interactions, (i.e., the role of oceanic adjustment versus stochastic wind forcing such as wind bursts). In this paper insight is gained into the role of the ocean within zonal mode events by means of an energetics analysis. The results obtained suggest that interannual variability within the equatorial Atlantic may largely be regarded as a modulation of seasonally active coupled processes and that the delayed oscillator mechanism does not sustain coupled climate oscillations on interannual time scales. The analysis conducted suggests that zonal mode events are due to interannual variability in the timing or intensity of the Bjerknes feedback that is excited seasonally between April and July and its associated thermocline mode. While interannual variability in the background potential energy (BPE) of the tropical Atlantic appears to play a role in driving interannual variability in the intensity of the seasonally excited Bjerknes feedback, not all zonal mode events are led by the appropriate BPE anomaly. Therefore, atmospheric variability associated with remote atmospheric forcing, with stochasticity of the atmosphere or with the meridional mode, appears to also play an important role in modulating the timing and intensity of the seasonally excited Bjerknes feedback.

The layout of this paper is as follows. Section 2 details the data and methods employed within this study. Section 3 contains the analysis and discussion and has been divided into three subsections. First, section 3 a explores the relationship between interannual anomalies in equatorial Atlantic APE, central-eastern basin SST, and western basin wind stress. The agreement between the result obtained in section $3 \mathrm{a}$ and previous studies illustrates that APE succinctly quantifies the response of the upper equatorial ocean to large-scale wind forcing anomalies associated with zonal mode events. Section $3 \mathrm{~b}$ illustrates that the physical processes associated with the development and decay of zonal mode events are the same as those that are seasonally active, except modulated either in phase or amplitude. Third, section $3 \mathrm{c}$ explores whether anomalous BPE within the equatorial Atlantic during April-May is associated with the anomalous evolution of the seasonally excited Bjerknes feedback that gives rise to zonal mode events. Finally, conclusions are drawn in section 4 .

\section{Data and methods}

\section{a. Evaluating $A P E$ and $B P E$}

In this study, available potential energy and background potential energy (BPE) are the energetic quantities of interest as they provide a concise evaluation of basinwide changes in zonal thermocline slope and mean thermocline depth in response to large-scale atmospheric forcing. Formalized by Lorenz (1955), the available potential energy of a fluid volume is defined as the difference in potential energy (PE) between its physical state and a rest state of minimum potential energy. In the oceanic context the fluid is assumed incompressible and so the effect of pressure on density during the leveling process is neglected $\left(\rho_{r}=\rho\right)$ (Oort et al. 1989; Huang 1998):

$$
\mathrm{APE}=\underbrace{\iiint g \rho z d V}_{\mathrm{PE}}-\underbrace{\iiint g \rho z_{*} d V}_{\mathrm{BPE}}=\iiint g \rho\left(z-z_{*}\right) d V,
$$

where $g$ is the acceleration due to gravity, $\iiint g \rho z d V$ is the physical PE of the fluid volume, and $\iiint g \rho z_{*} d V$ the minimum PE attainable through the reversible adiabatic redistribution of mass, a rest state in which all 
density surfaces are level, referred to as the BPE. For the fluid parcel at position $(\mathbf{x}, t)$ and depth $z$ with density $\rho, z_{*}(\mathbf{x}, t)$ is its vertical position in the reference state of minimum PE. The vertical position of each water parcel in the rest state is determined following (Huang 1998). The $V(\mathbf{x}, t)$ is the volume beneath the center of the fluid parcel, $\rho(\mathbf{x}, t)$, once moved to its rest state position according to $V(\mathbf{x}, t)=\iiint H\left[\rho\left(\mathbf{x}^{\prime}, t\right)-\rho(\mathbf{x}, t)\right] d V^{\prime}$, where $H$ is a Heaviside step function satisfying $H(y)=0$ for $y<$ $0, H(y)=0.5$ for $y=0$ and $H(y)=1$ for $y>0$ (Winters et al. 1995; Huang 1998). The corresponding vertical coordinate $z_{*}(\mathbf{x}, t)=z[V(\mathbf{x}, t)]$ is then found based on the fact that the volume above the bottom of the chosen domain is a function of $z$.

See Burls (2010) and Burls et al. (2011) for an explanation as to why, unlike previous studies of equatorial energetics in the Pacific (Goddard and Philander 2000; Fedorov et al. 2003; Fedorov 2007), we chose not to use an approximation for APE that assumes APE can then be described by its leading order Taylor-expanded term (Reid et al. 1981; Oort et al. 1989) and the background rest state (the BPE of the fluid volume) is fixed in time.

$\mathrm{APE}$ and BPE are nonlinear terms and in calculating their climatological values the climatological average of the product of interannual perturbations is neglected as the contribution of this term is seen to be small (Burls 2010):

$$
\begin{aligned}
\mathrm{APE}_{\mathrm{cl}} & \approx \iiint g \rho_{\mathrm{cl}}\left(z-z_{* \mathrm{cl}}\right) d V, \\
\mathrm{BPE}_{\mathrm{cl}} & \approx \iiint g \rho_{\mathrm{cl}} z_{*_{\mathrm{cl}}} d V .
\end{aligned}
$$

\section{b. Datasets}

The analysis conducted in section $3 \mathrm{a}$ is based on three datasets to illustrate the robustness of the results across different sources of data and time periods. Interannual anomalies in equatorial Atlantic APE $\left(3^{\circ} \mathrm{S}-3^{\circ} \mathrm{N}\right.$, $\left.60^{\circ} \mathrm{W}-15^{\circ} \mathrm{E}, 0-400 \mathrm{~m}\right), \mathrm{SST}$ over the Atl 3 region $\left(3^{\circ} \mathrm{S}-3^{\circ} \mathrm{N}\right.$, $20^{\circ} \mathrm{W}-0^{\circ}$ - an index commonly used when evaluating interannual SST variability associated with the zonal mode), and western basin wind stress $\left(5^{\circ} \mathrm{N}-5^{\circ} \mathrm{S}, 40^{\circ}-20^{\circ} \mathrm{W}\right)$ have been calculated using the temperature, salinity, and wind forcing fields from

1) The $1 / 2^{\circ}$ Simple Ocean Data Assimilation (SODA) reanalysis product (Carton and Giese 2008), spanning 50 years (1958-2007),

2) The $1 / 3^{\circ}$ latitude by $1^{\circ}$ longitude Global Ocean Data Analysis System (GODAS) analysis product (Behringer and Xue 2004) spanning 31 years (19802011), and
3) a simulation of oceanic conditions within the tropical Atlantic between 1980 and 2004 conducted using the Regional Ocean Modeling System (ROMS), hereafter referred to as ROMS-TAtl.

ROMS is a split-explicit, free-surface, sigma (terrain following) coordinate ocean model based on the primitive equations with the Boussinesq and hydrostatic approximations made (Shchepetkin and McWilliams 2005). The ROMS-TAtl simulation has a Mercator grid extending zonally from $60^{\circ} \mathrm{W}$ to $15^{\circ} \mathrm{E}$ and meridionally from $10^{\circ} \mathrm{S}$ to $14^{\circ} \mathrm{N}$ with a horizontal resolution of $\sim 1 / 6^{\circ}$. After some experimentation with the meridional extent of this domain, the northern and southern open boundaries were chosen such that the domain was large enough to resolve all relevant features within the equatorial Atlantic but still small enough for the equatorial thermocline to be adequately constrained by the prescribed lateral boundary conditions (it was found that the larger the chosen domain the more diffuse the equatorial thermocline). The adaptive algorithm of Marchesiello et al. (2001), where inward and outward information fluxes at the open boundaries are treated separately, was used to deal with the open boundaries. Inward fluxes were nudged toward external data with prescribed surface elevation, barotropic horizontal velocity, baroclinic horizontal velocity, temperature, and salinity provided by the SODA reanalysis product (Carton et al. 2000; Carton and Giese 2008). The surface vertical boundary conditions were provided by a bulk formula (Kondo 1975) derived from atmospheric parameters supplied by the National Centers for Environmental Prediction-Department of Energy (NCEP-DOE II), reanalysis product (Kanamitsu et al. 2002). The simulation was spun up for 10 years using lateral and surface boundary conditions for 1980, the first year of the simulation period. Thereafter the model was forced with interannually varying surface and lateral boundary conditions from 1980 to 2004. For a more detailed description and validation of the ROMS-TAtl configuration, see Burls (2010).

The ROMS-TAtl simulation was undertaken to acquire the temperature, salinity, and momentum evolution equations tendency terms required to evaluate the processes determining APE, BPE, and kinetic energy (KE) evolution. The evolution equations employed in section $3 \mathrm{~b}$ when evaluating the dominant processes responsible for interannual APE anomalies within an open boundary equatorial and tropical Atlantic domain are given in the appendix. Density values required to calculate APE and BPE and their tendency terms have been derived from the simulated ROMS-TAtl temperature and salinity fields (which observe the tracer conservation equation) using a linear equation of state. The 


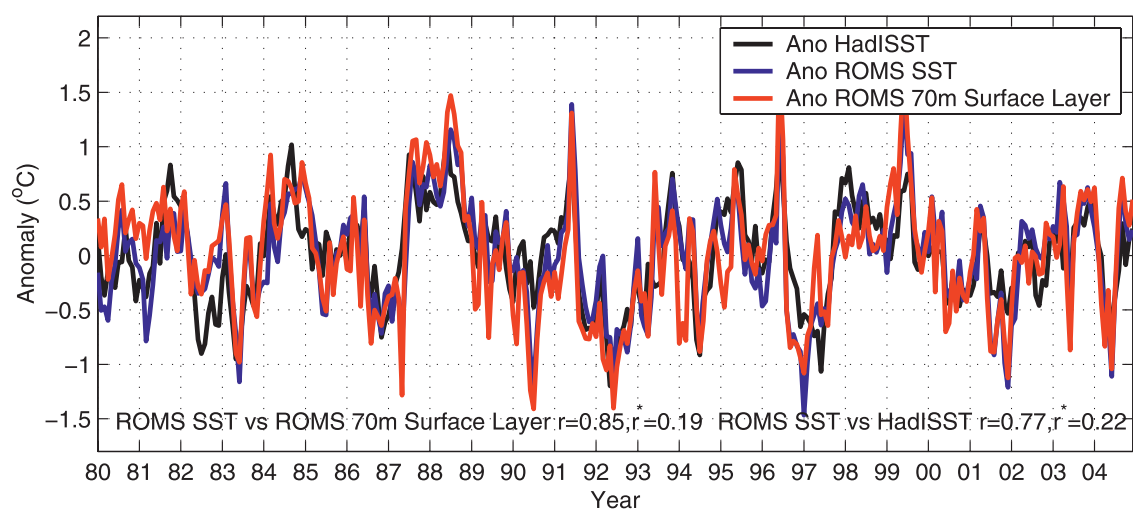

FIG. 1. A comparison between Atl3 SST anomalies $\left({ }^{\circ} \mathrm{C}\right)$ created using detrended HadISST data (Rayner et al. 2003) and ROMS-TAtl SST data. The correlation between each SST index $(r)$ is given, together with the required correlation value for significance at the $95 \%$ level taking into account the effective degrees of freedom $\left(r^{*}\right)$. The relationship between anomalies in ROMS-TAtl SST and the mean temperature of the upper 70-m layer for the Alt3 region is also shown.

use of a linear equation of state ensures that the density field is conserved. This linear approximation is shown to be valid in Burls (2010) and Burls et al. (2011). Note that for the analysis based on SODA and GODAS temperature and salinity fields a nonlinear equation of state was used to estimate the density field (Jackett and McDougall 1995) as the APE, BPE, and KE evolution analysis was only based on ROMS output and, hence, density conservation was only required of the ROMS density field.

Figure 1 compares observed Atl3 SST anomalies derived from monthly Hadley Centre Sea Ice and SST dataset (HadISST) with those derived from ROMS-TAtl SST (1980-2004). The ROMS-TAtl simulation has managed to capture a significant percentage $\left(r=0.77 r^{*}=0.22\right.$ : $r^{*}$ represents the required correlation value for significance at the $95 \%$ level, taking into account the effective degrees of freedom) of the interannual variability observed in Atl3 SST. To ensure that this skill is not purely due to the fact that SST may be somewhat constrained to observed surface air temperatures by the bulk formulation of surface heat fluxes, the interannual variability in ROMS Atl3 SST is compared with that of the mean temperature of the upper $70 \mathrm{~m}$ layer that corresponds to the mean depth of the thermocline for the Atl3 region. The surface heat flux term plays a secondary role to vertical advection in driving the temperature fluctuations of this layer (Burls 2010; Burls et al. 2011). As shown in Fig. 1 a correlation of $r=0.85\left(r^{*}=0.19\right)$ is seen between anomalies in SST and the mean temperature of this 70-m-deep surface layer, indicating the importance of ocean dynamics in determining the simulated SST variability.

Further validation of the ROMS-TAtl simulation conducted in Burls (2010) and Burls et al. (2011) provides confidence in the ROMS-TAtl solution, as seasonal and interannual variability in the tropical Atlantic is shown to be reproduced reasonably well.

\section{Results and discussion}

a. The relationship between interannual anomalies in equatorial Atlantic APE and Atl3 SST

Figures $2 \mathrm{a}$ and $2 \mathrm{~b}$ depict the relationship between interannual anomalies in the equatorial Atlantic APE $\left(3^{\circ} \mathrm{S}-3^{\circ} \mathrm{N}, 60^{\circ} \mathrm{W}-15^{\circ} \mathrm{E}, 0-400 \mathrm{~m}\right)$ and Atl 3 SST based on SODA data and GODAS data, respectively. The maximum correlation between equatorial Atlantic APE and Atl3 SST is observed at zero lag with a correlation coefficient of $r=-0.56\left(r^{*}=-0.17\right)$ based on the SODA data from 1958-2007 (Fig. 2a) and a slightly higher correlation coefficient of $r=0.63\left(r^{*}=-0.18\right)$ based the GODAS data from 1980-2011 (Fig. 2b). The APE-SST relationship observed in Figs. $2 \mathrm{a}, \mathrm{b}$ is indicative of the significant role remotely forced thermocline depth variations play in interannual At13 SST variability. This relationship is, however, considerably weaker than the corresponding relationship in the Pacific (Goddard and Philander 2000), a result that is in agreement with the weaker relationship observed between interannual SST anomalies and thermocline depth anomalies in the centraleastern equatorial Atlantic (Zebiak 1993; Vauclair and du Penhoat 2001; Keenlyside and Latif 2007).

Figures $2 \mathrm{c}$ and $2 \mathrm{~d}$ explore the seasonality in the relationship between these two variables. The seasonal dependence in the correlation between interannual anomalies in equatorial Atlantic APE and Atl3 SST observed in Figs. 2c,d is similar, anomalous At13 SST correlates best with anomalous APE between April and August. This finding 
(a)

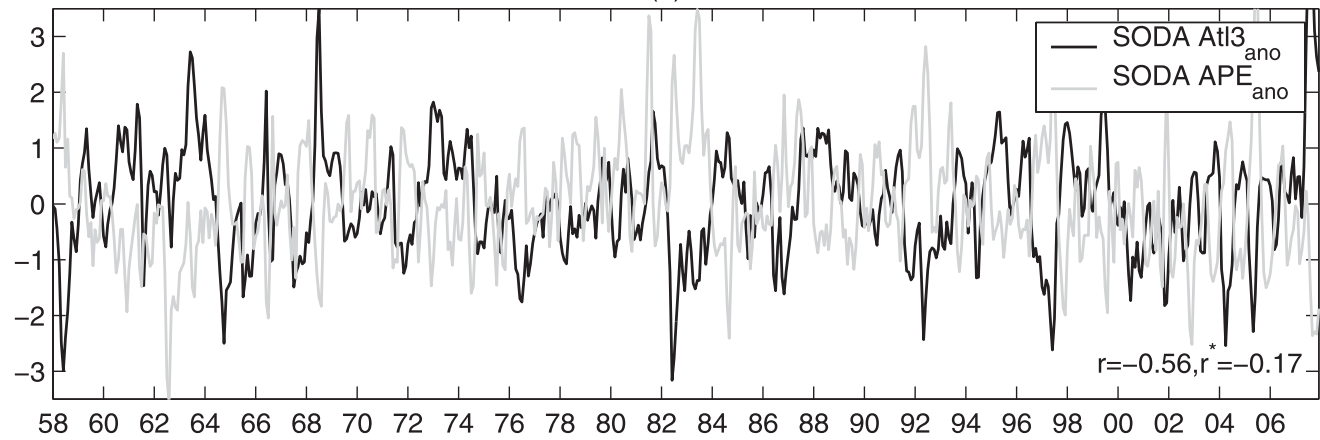

(b)

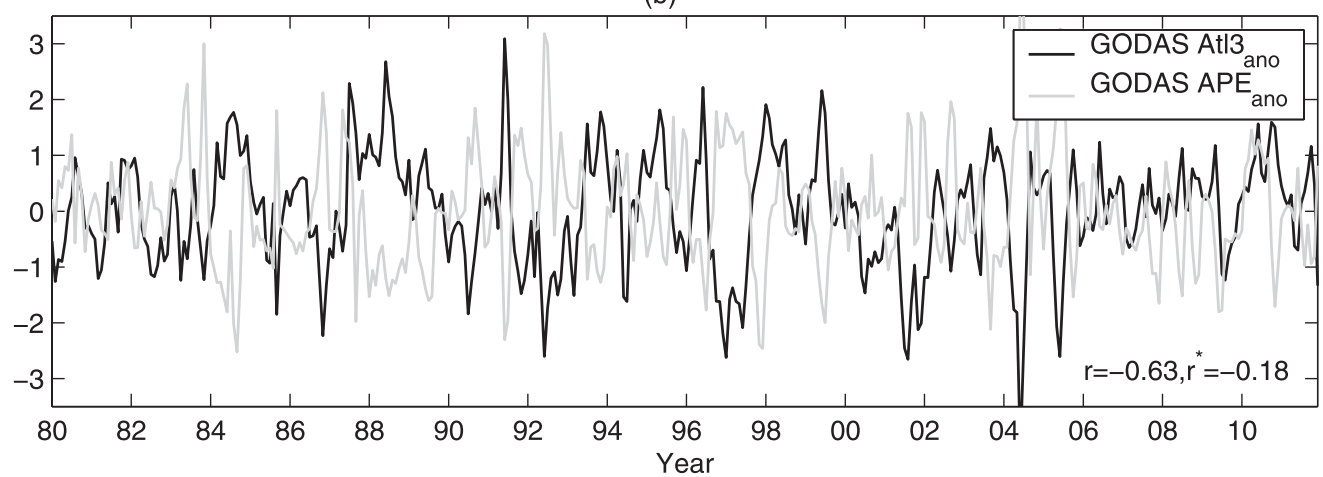

$\mathrm{APE}_{\text {ano }}<=>\mathrm{Atl3}_{\text {ano }}^{(\mathrm{c})}: 1958-2007$

(d)

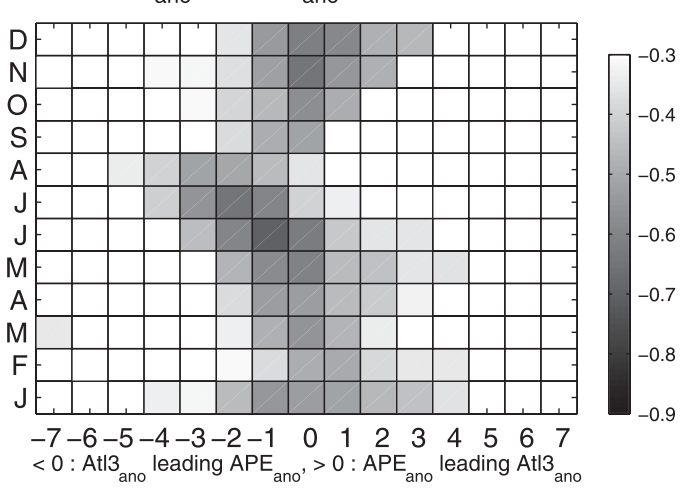

$\mathrm{APE}_{\text {ano }}<=>\mathrm{Atl}_{\text {ano }}^{(\mathrm{d})}: 1980-2011$

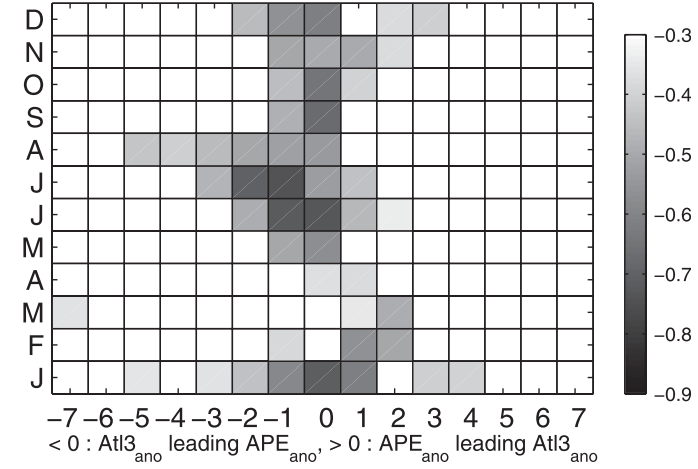

FIG. 2. A comparison between normalized interannual Atl3 SST and equatorial Atlantic $\left(3^{\circ} \mathrm{S}-3^{\circ} \mathrm{N}, 60^{\circ} \mathrm{W}-15^{\circ} \mathrm{E}\right.$, 0-400 m) APE anomalies, calculated using (a) SODA data and (b) GODAS data. The correlation between anomalies $(r)$ is given, together with the required correlation value for significance at the $95 \%$ level taking into account the effective degrees of freedom $\left(r^{*}\right)$. (c),(d) The seasonal dependence in correlations between these SST and APE anomalies. Only correlations significant above the 95 percentile are shown. SST and APE anomalies were calculated based on (c) SODA data and (d) GODAS output.

is also in agreement with seasonality in the regression between SST and thermocline depth anomalies (assessed using sea level anomalies as a proxy) obtained by Keenlyside and Latif (2007) and is consistent with the fact that zonal mode events peak in boreal summer (Zebiak 1993; Keenlyside and Latif 2007). Also worth noting is the secondary peak in the correlation between anomalous equatorial APE and Atl3 SST visible in Figs. 2c,d between November and January. This secondary peak corresponds with the secondary peak in interannual central equatorial Atlantic SST variability identified by Okumura and Xie (2006). Okumura and Xie attribute this secondary seasonal peak to a November-December zonal mode of coupled variability. On the other hand, between January and April the correlation between interannual anomalies in equatorial Atlantic APE and At13 SST drops substantially (Figs. 2c,d). 
(a)

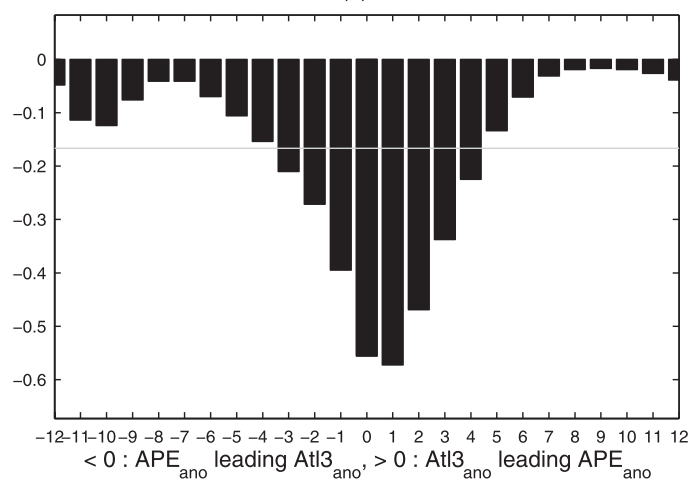

(c)

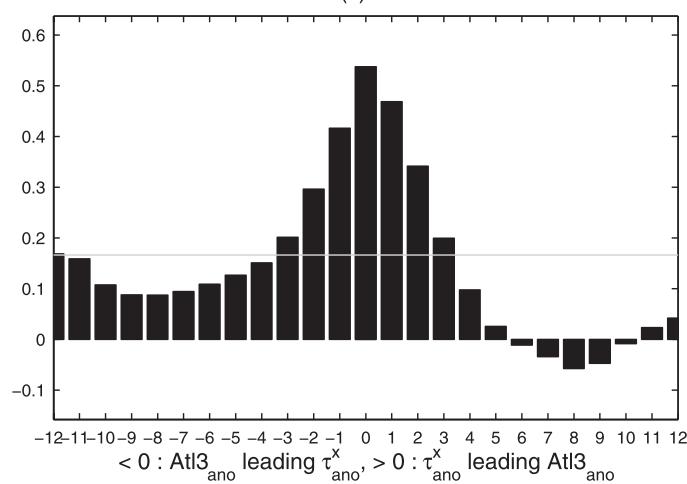

(e)

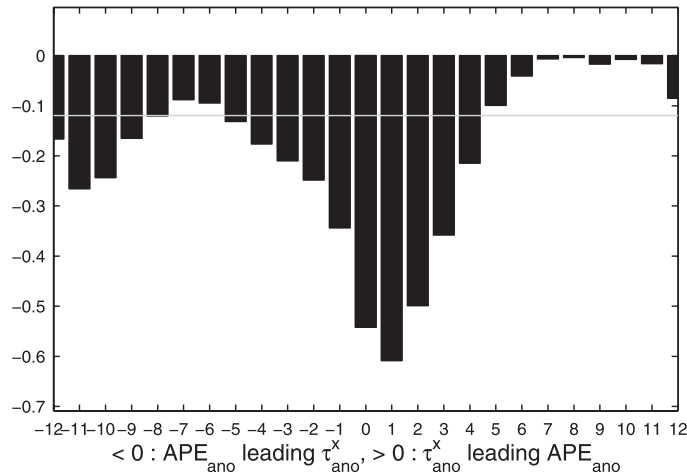

(b)

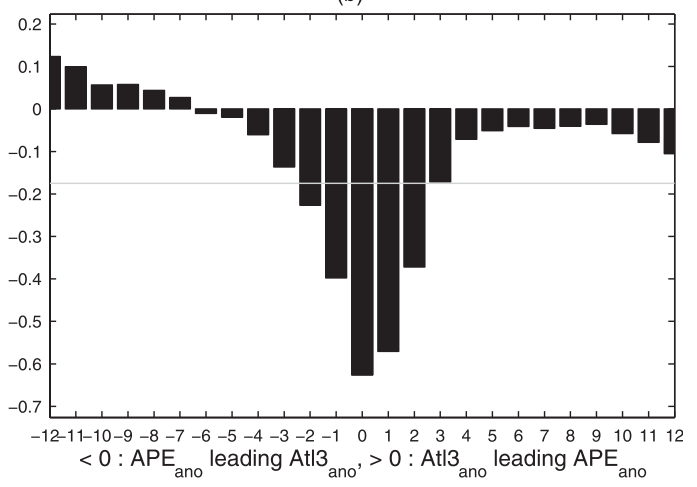

(d)

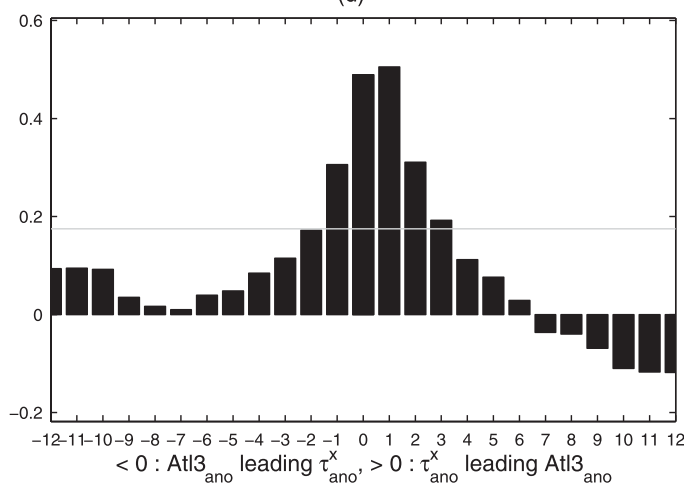

(f)

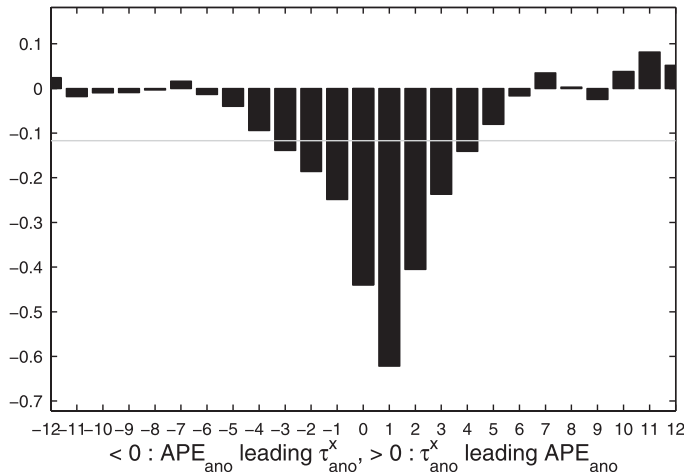

FIG. 3. Time lag correlations between detrended anomalous Atl3 SST and equatorial Atlantic APE $\left(3^{\circ} \mathrm{S}-3^{\circ} \mathrm{N}\right.$, $60^{\circ} \mathrm{W}-15^{\circ} \mathrm{E}, 0-400 \mathrm{~m}$ ) based on (a) SODA data and (b) GODAS data. Time lag correlations between anomalous At13 SST and detrended western equatorial Atlantic $\left(5^{\circ} \mathrm{N}-5^{\circ} \mathrm{S}, 40^{\circ}-20^{\circ} \mathrm{W}\right)$ zonal wind stress based on (c) SODA data and (d) GODAS data. Time lag correlations between anomalous equatorial Atlantic APE and western equatorial Atlantic zonal wind stress based on (e) SODA data and (f) GODAS data.

Furthermore, the relationship between anomalous western Atlantic zonal wind stress and Atl3 SST peaks in June (not shown; see Burls 2010) and the strongest relationship between anomalous western Atlantic zonal wind stress and equatorial APE is observed in June-July (not shown; see Burls 2010). This seasonality is consistent with the observationally based findings of Keenlyside and Latif (2007).

Figure 3 shows that for both SODA and GODAS datasets the time lag-lead correlations between anomalous
(Figs. 3a and 3b) Atl3 SST and equatorial Atlantic APE (Figs. 3c and 3d), Atl3 SST and western Atlantic zonal wind stress, and (Figs. 3e and 3f) western Atlantic zonal wind stress and equatorial Atlantic APE are all fairly symmetric about zero lag. As in Keenlyside and Latif, these symmetric lag-lead correlations suggest that the covariability observed is the result of a positive feedback with anomalies in each variable reinforcing one another (Frankignoul and Hasselmann 1977). 
(a)

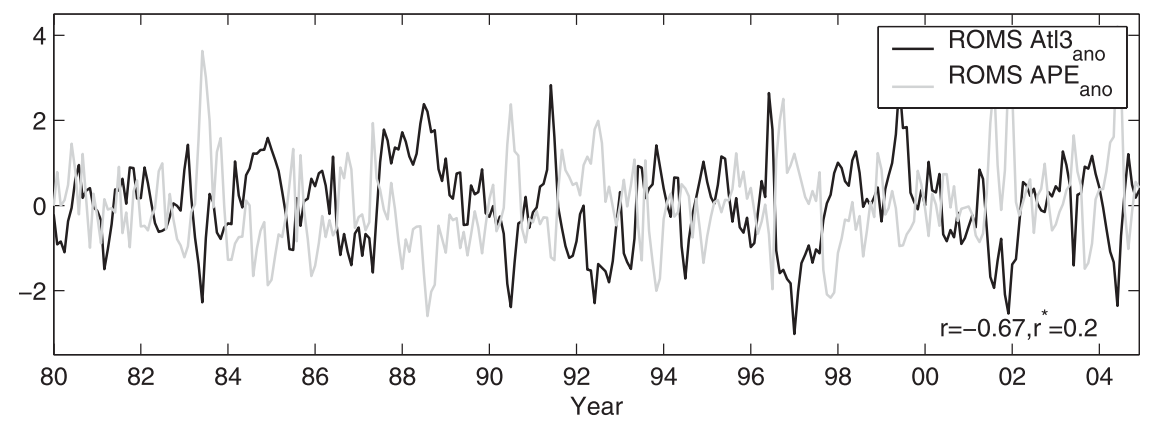

$\mathrm{APE}_{\text {ano }}<=>\mathrm{Atl}_{\text {ano }}^{(\mathrm{b})}: 1980-2004$

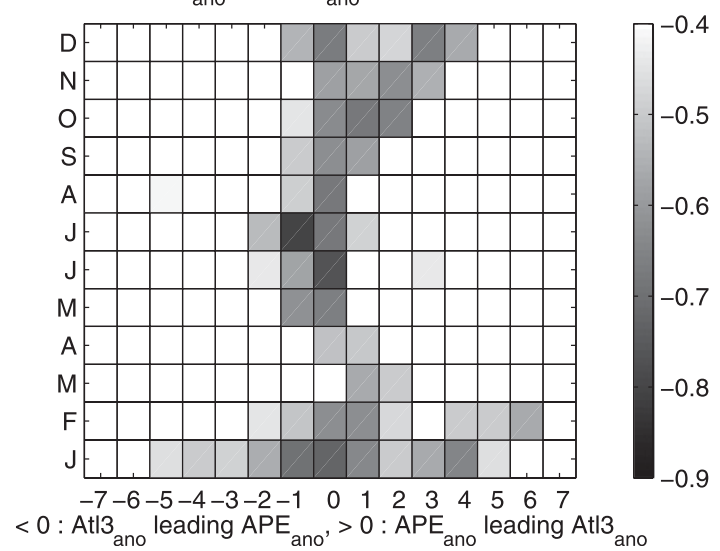

FIG. 4. As in Fig. 2, but SST and APE anomalies were calculated using ROMS-TAtl data.

These results are consistent with the findings of Keenlyside and Latif (2007), who suggest that the Bjerknes feedback is active interannually in the equatorial Atlantic and that seasonal variations in the influence of SSTs on surface winds, as well as seasonal variability in subsurface-surface coupling, point to the fact that the Bjerknes feedback is predominately active between April and August. However, in light of results presented in Burls et al. (2011) suggesting that the Bjerknes is seasonally active between April and August, we suggest that anomalous SST events in the At13 region forced by the Bjerknes feedback mechanism occur predominantly during boreal summer as a modulation of an already seasonally active Bjerknes feedback that forms part of a seasonally excited thermocline mode. The weaker relationship that occurs outside of this season, in particular between January and April, suggests that SST anomalies during these periods of the year are more likely to be the result of remote forcing or a different local air-sea interaction process.

Figures 4 and 5 are the equivalent of Figs. 2 and 3, respectively, except that they are based on the ROMS-TAtl simulation. Figure $4 \mathrm{a}$ shows the relationship between interannual anomalies in the equatorial Atlantic APE $\left(3^{\circ} \mathrm{S}-3^{\circ} \mathrm{N}, 60^{\circ} \mathrm{W}-15^{\circ} \mathrm{E}, 0-400 \mathrm{~m}\right)$ and Atl3 SST based on ROMS-TAtl data. The maximum correlation between equatorial Atlantic APE and Atl3 SST is observed at zero lag with a correlation coefficient of $r=-0.67$ $\left(r^{*}=-0.2\right)$. Figure $4 \mathrm{~b}$ explores the seasonality in the relationship between Atl3 SST and APE. The seasonal dependence in the correlation between interannual anomalies in equatorial Atlantic APE and Atl3 SST observed is similar to that seen in Figs. 2c,d; anomalous At13 SST correlates best with anomalous APE between April and August. Likewise, the lag-lead correlations seen in Fig. 5 are all fairly symmetric about zero lag resembling those in Fig. 3. The agreement between the result obtained here based on SODA and GODAS reanalysis data, the ROMS-TAtl simulations, as well as previous studies provides confidence in the ROMSTAtl simulation upon which the analyses within the next two results section are based.

\section{b. Interannual modulations of the seasonally excited thermocline mode}

In this section, by means of composite analysis, an investigation into the dominant processes responsible 
(a)

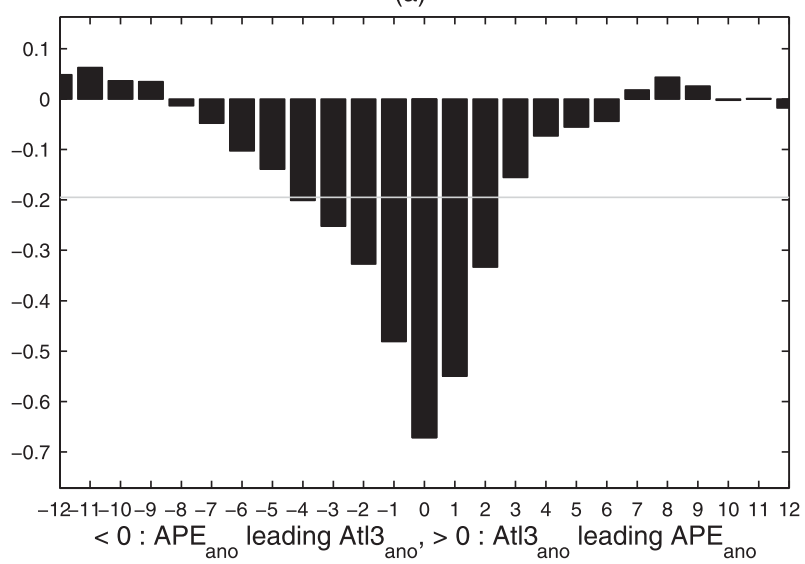

(b)

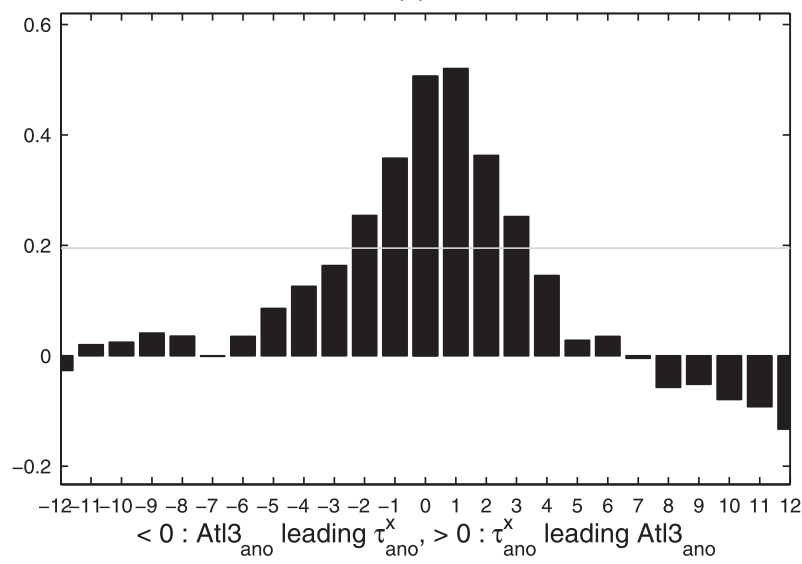

(c)

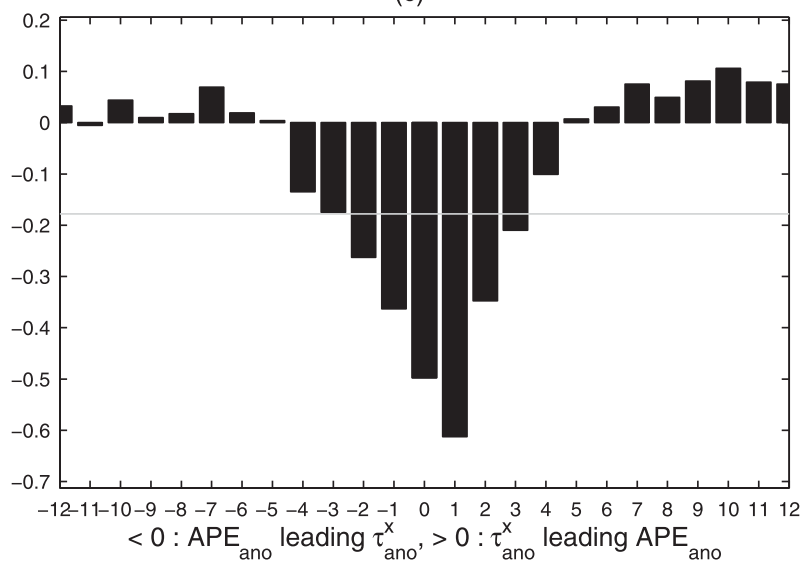

FIG. 5. As in Fig. 3, but anomalies were calculated using ROMS-TAtl data.

for APE anomalies, and an analysis of individual events, we illustrate that interannual variability in Atl3 SST correlated with anomalous APE can largely be regarded as interannual modulations of the thermocline mode that is excited seasonally when the cold tongue develops (Burls et al. 2011).

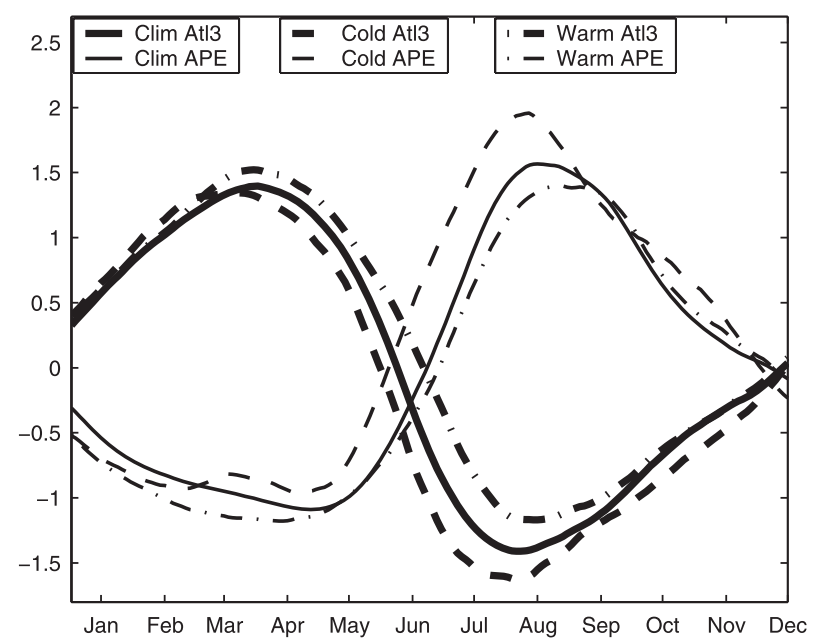

FIG. 6. Climatological values of Atl3 SST (thick lines) and equatorial Atlantic $\left(3^{\circ} \mathrm{S}-3^{\circ} \mathrm{N}, 60^{\circ} \mathrm{W}-15^{\circ} \mathrm{E}, 0-400 \mathrm{~m}\right)$ APE (thin lines) are compared with cold (1983, 1986, 1992, 1994, and 2004) and warm $(1984,1987,1988,1991,1995,1996,1998$, and 1999) year composites of Atl3 SST and equatorial Atlantic APE. Values were calculated based on ROMS-TAtl and have been normalized.

\section{1) Composite Analysis}

To establish a clear picture of the energetics associated with warm and cold zonal mode events, composites of years when cold/warm Atl3 SST events occurred during boreal summer months (June-August) have been created. Here, warm/cold event years are defined as years in which ROMS-TAtl Atl3 SST anomalies exceed one standard deviation $\left(0.5^{\circ} \mathrm{C}\right)$ between June and August of that year, and correspond well with observed HadISST (Rayner et al. 2003) Atl3 SST anomalies (Fig. 1). Cold event years have been identified as 1983, 1986, 1992, 1994, and 2004 and warm event years as 1984, 1987, 1988, 1991, 1995, 1996, 1998, and 1999. The 1984, 1987, 1988, 1991, 1995, and the 1998 warm events have been investigated in previous studies based on observed and model data (Carton and Huang 1994; Vauclair and du Penhoat 2001; Vauclair et al. 2004).

Considering anomalous conditions within the context of climatological conditions, Fig. 6 compares the typical evolution of Atl3 SST and equatorial APE during cold and warm event years with their climatological evolution. Typical of the cold events is anomalously high equatorial and tropical Atlantic APE values peaking in June/July. Figure 6 suggests that these equatorial APE and Atl3 SST anomalies are typically the results of an amplified and/or early onset of SST and APE changes driven by the seasonal development of the equatorial cold tongue.

On the other hand, zonal-mode warm events are typified by anomalously low equatorial and tropical 
APE values (Fig. 6) with the negative APE anomaly typically reaching its maximum in July/August. Figure 6 suggests that, during warm events, boreal summer SST (APE) anomalies result from the suppression of the seasonal decline (increase) in SST (APE) typically associated with the development of the equatorial cold tongue and its associated Bjerknes feedback.

If the correlated interannual SST and APE variability during boreal summer months is in fact the result of interannual modulations of the thermocline mode that is seasonally excited during these months, then we would expect the physical processes associated with the development of these anomalous events to be the same as those that are seasonally active, but modulated.

2) THE DOMINANT PROCESSES RESPONSIBLE FOR THE GROWTH AND DECAY OF APE ANOMALIES

\section{(i) The anomalous APE-wind power relationship}

Following the methodology outlined in the appendix, the contribution of each term to the evolution of equatorial $\left(3^{\circ} \mathrm{S}-3^{\circ} \mathrm{N}, 60^{\circ} \mathrm{W}-15^{\circ} \mathrm{E}, 0-400 \mathrm{~m}\right)$ and tropical $\left(8^{\circ} \mathrm{S}-\right.$ $8^{\circ} \mathrm{N}, 60^{\circ} \mathrm{W}-15^{\circ} \mathrm{E}, 0-400 \mathrm{~m}$ ) Atlantic APE [Eq. (A1)] has been estimated and, then, climatological values (as defined in section 2a) have been subtracted to establish interannual anomalies. In their assessment of the processes dictating climatological equatorial and tropical Atlantic APE changes, Burls et al. (2011) found that both equatorial and tropical basin APE changes are driven primarily by the buoyancy power term [Eq. (A1)]. Likewise, the dominant term driving interannual anomalies in equatorial and tropical Atlantic APE is seen to be the buoyancy power term. A correlation coefficient of $r=0.78\left(r^{*}=0.19\right)$ is seen between monthly anomalies in buoyancy power and APE evolution for the equatorial Atlantic and a correlation coefficient of $r=0.89\left(r^{*}=0.19\right)$ for the tropical Atlantic. The approximation that equatorial/tropical basin APE changes are driven primarily by buoyancy forcing associated with the horizontal redistribution of warm surface waters is therefore seen to hold when evaluating anomalous APE changes in the Atlantic [Eq. (4)]:

$$
\frac{d \mathrm{APE}_{\mathrm{ano}}}{d t} \approx \underbrace{\int .}_{\Phi_{\mathrm{apk}_{\mathrm{ano}}} \iiint g \tilde{\rho} w d V-\iiint g \tilde{\rho}_{\mathrm{cl}} w_{\mathrm{cl}} d V}
$$

The buoyancy power term is the reversible exchange term between the APE and KE evolution equations, so further insight can be gained into the processes responsible for anomalous buoyancy power and, hence, anomalous APE evolution by considering the KE evolution equation [Eq. (A2)]. The contribution of each term to the KE evolution equation has been estimated and then climatological values have been subtracted to establish the terms driving KE evolution on interannual time scales.

For both equatorial and tropical Atlantic domains, anomalous fluctuations in the buoyancy power term are compared with anomalous fluctuations in the primary source term, namely, the wind power term. Like the results obtained in Burls et al. with regards to the seasonal cycle, anomalous buoyancy power corresponds well with anomalous wind power within the tropical Atlantic domain but not within the equatorial domain. A correlation coefficient of $r=0.34\left(r^{*}=-0.19\right)$ is found between monthly anomalies in buoyancy power and wind power for the equatorial Atlantic and a correlation coefficient of $r=0.67\left(r^{*}=0.19\right)$ for the tropical Atlantic. As in Burls et al. (2011) and Goddard and Philander (2000), this difference is thought to be due to the larger influence of processes acting at the boundaries of the equatorial domain than the tropical domain, as transients (Rossby and Kelvin waves), excited by wind stress fluctuations, enter and exit the equatorial domain. For the equatorial domain, changes in APE are largely controlled not only by anomalous work done by the wind within the equatorial domain but also by anomalous processes acting at the boundaries $\left(\Phi_{p w_{\text {ano }}}\right.$ and $\left.\Phi_{k a_{\text {ano }}}\right)$. On the other hand, anomalous APE changes within the tropical domain are seen to be largely due to anomalous work done by the wind within the tropical domain. Extending the domain over which APE is evaluated poleward therefore simplifies the dynamics governing interannual APE variability down to a single dominant process, namely, the work done by the wind over the tropical Atlantic.

A correlation coefficient of $r=0.66\left(r^{*}=-0.19\right)$ is seen between anomalous APE evolution and anomalous wind power. This result is consistent with the fact that anomalous APE evolution within the tropical domain is driven predominantly by buoyancy power anomalies and that the source of these buoyancy power anomalies in the KE energy evolution equation is largely due to anomalous wind power. The relationship between anomalous APE evolution and anomalous wind power is particularly strong during boreal summer (Burls 2010).

The meridional extension of the domain over which APE is evaluated does not have a large effect on the Atl3 SST-APE relationship. Interannual anomalies in tropical Atlantic APE are highly correlated with those in equatorial Atlantic APE $\left[r=0.86\left(r^{*}=-0.19\right)\right]$ with the maximum correlation occurring at zero lag. Subsequently the relationship between anomalous Atl3 SST and APE decreases only slightly when one extends the domain over which APE is evaluated to include the tropical domain. The maximum correlation is observed at zero lag with 
a correlation coefficient of $r=-0.59\left(r^{*}=-0.19\right)$. The meridional extent of the tropical domain chosen here, $8^{\circ} \mathrm{S}-8^{\circ} \mathrm{N}$, is deemed large enough to encompass the windforced region over which buoyancy power anomalies are predominantly related to wind power anomalies, yet small enough to preserve the strong relationship with Atl3 SST.

Returning to the composite analysis discussed in section $3 b(1)$, Fig. 7 shows that tropical Atlantic wind power values between January and July are typically larger than normal during cold event years. Conversely, during warm event years, anomalously low APE between June and August results from anomalously weak wind power between April and July (Figs. 6 and 7).

Considering the significant relationship between anomalous equatorial and tropical Atlantic APE and At13 SST and the fact that anomalous tropical Atlantic APE is largely forced by tropical Atlantic wind power anomalies, one would expect anomalous wind power events to lead to anomalous At13 SST events. Figure 8a shows the lag-lead relationship between anomalous tropical Atlantic wind power and anomalous Atl3 SST (note a 3-month running mean has been applied to each time series). Tropical Atlantic wind power anomalies are seen to lead Atl3 SST anomalies by 1-2 months (Fig. 8a). A maximum anticorrelation of $r=-0.58$ is found between tropical Atlantic wind power and Atl3 SST when the former leads by 1 month (Fig. 8a).

Figure $8 \mathrm{~b}$ explores whether there is any seasonal dependence in the lag-lead correlation between monthly Atl3 SST and tropical Atlantic wind power anomalies. The weakest correlation between wind power and Atl3 anomalies regardless of the lag or lead time occurs between January and April (Fig. 8b). Consistent with the results obtained in Keenlyside and Latif (2007), Lübbecke et al. (2010), and Burls (2010), it is during these months that subsurface temperature anomalies associated with thermocline depth variability are less readily reflected in the SST field. Seasonally, the surface mixed layer is decoupled from subsurface variability during these months, as the climatological wind stress over the Atl3 region is at its weakest and climatological atmospheric heating is at its strongest (Peter et al. 2006; Burls et al. 2011).

Significant, and roughly symmetric, lag-lead correlations between anomalous At13 SST and wind power are seen in Fig. 8b between April and July with anticorrelation values reaching a maximum at zero lag $(r<-0.75)$. This symmetric lag-lead relationship suggests that anomalies in each variable reinforce one another as opposed to purely a one-way forcing. As discussed in the following subsection, anomalous wind power during these months is believed to be predominantly due to anomalousBjerknes feedback induced-zonal wind stress anomalies acting on climatological zonal surface currents.

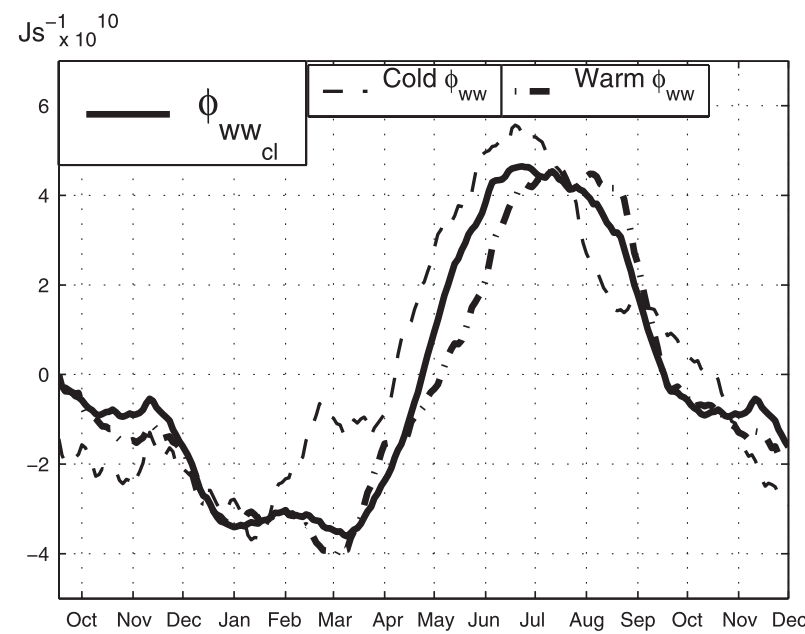

FIG. 7. Climatological values of tropical Atlantic $\left(8^{\circ} \mathrm{S}-8^{\circ} \mathrm{N}\right.$, $\left.60^{\circ} \mathrm{W}-15^{\circ} \mathrm{E}, 0-400 \mathrm{~m}\right)$ wind work $\left(\Phi_{\mathrm{ww}}\right)$ are compared with cold (1983, 1986, 1992, 1994, and 2004) and warm (1984, 1987, 1988, 1991, 1995, 1996, 1998, and 1999) year composites of wind work. Values (in $\mathrm{J} \mathrm{s}^{-1}$ ) were calculated based on ROMS-TAtl.

Between July and September, the highest correlation between At13 SST anomalies and wind power anomalies occurs when wind power anomalies lead by $1-2$ months (Fig. 8b). In the next subsection, anomalous wind power during these months is seen to be predominantly due to climatological wind stress acting on anomalous zonal surface currents. Furthermore, a significant portion of the anomalous wind work occurring between August and September is positively correlated with Atl3 SST anomalies occurring 3-4 months earlier (Fig. 8b). Climatological zonal wind stress acting on zonal surface current anomalies is shown in the next subsection to be responsible for this delayed opposing wind work.

From September to February the lead correlation between wind power and Atl3 anomalies increases from 2 months in September to 5 months in January. The exact reason for this growth in the lag-lead relationship between wind work and Atl3 SST anomalies is uncertain. One suggestion could be the greater persistence of Atl3 SST anomalies during these months as anomalous Atl3 conditions generally persist between September and February. This result suggests that anomalous, central-eastern basin SST variability associated with the November-December zonal mode of Okumura and Xie (2006) is related to anomalous wind power forcing during the preceding August-October months.

\section{(ii) Decomposing anomalous zonal wind power}

In Burls et al. (2011), zonal winds acting on zonal surface currents were seen to be responsible for most of the work done seasonally by the wind on the ocean within the tropical Atlantic. The zonal component is 
(a)

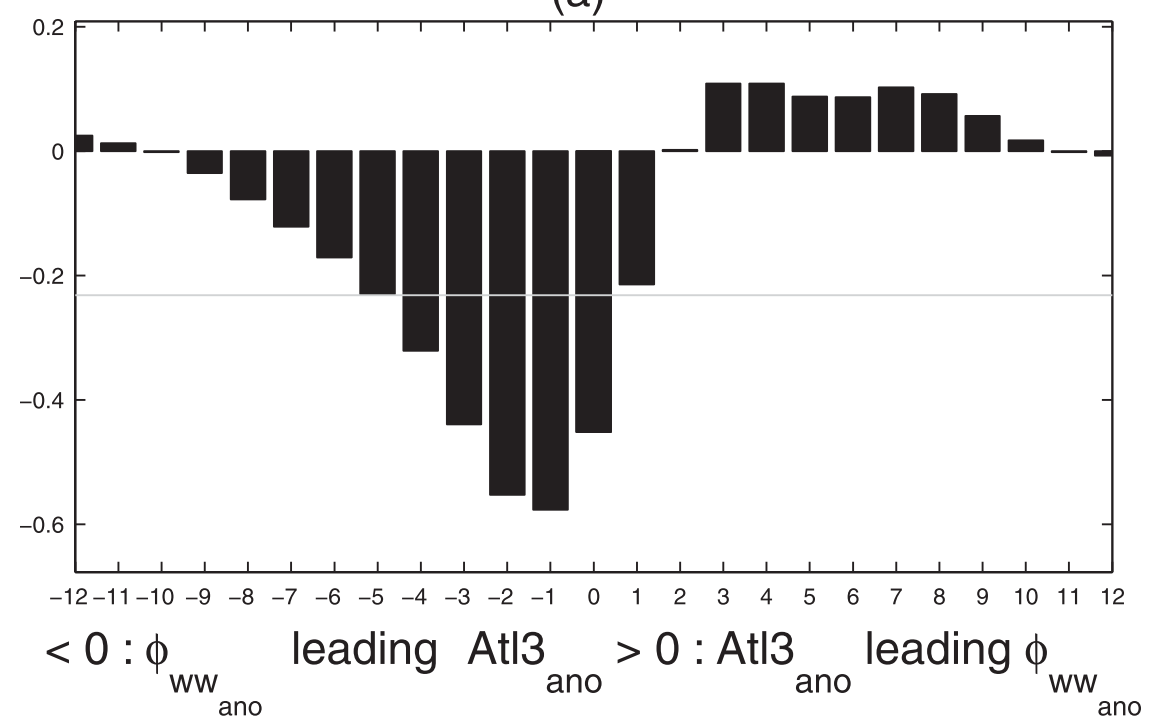

(b) Atl3 $_{\text {ano }}<=>\phi_{\text {ww }}: 1980-2004$

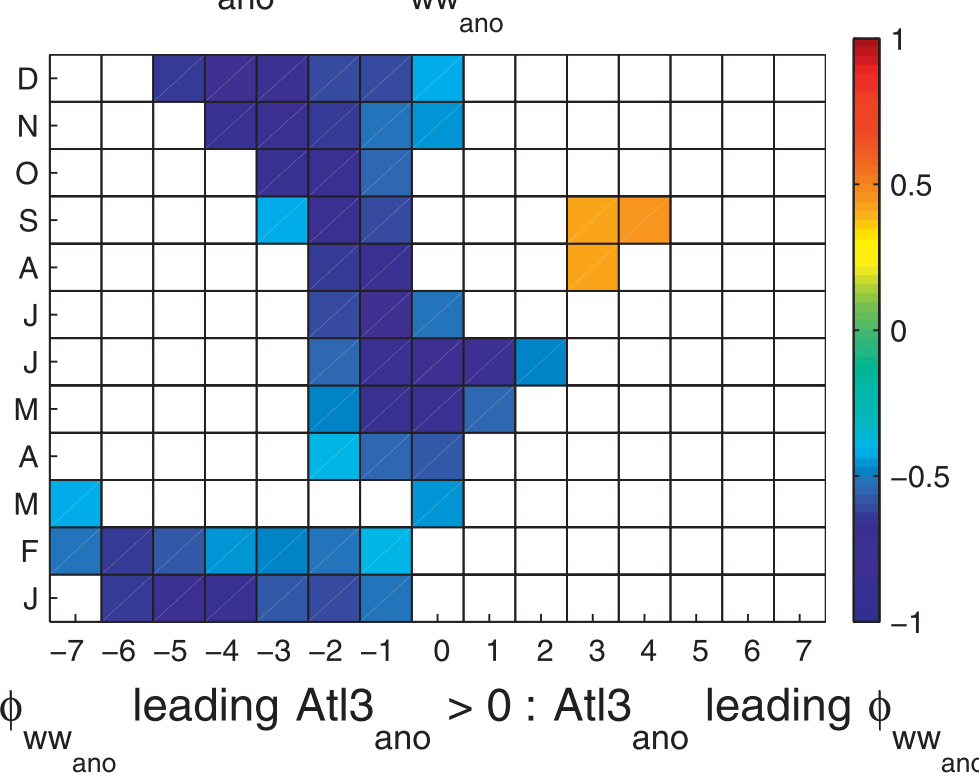

FIG. 8. (a) Time lag correlations between interannual Atl3 SST anomalies and tropical Atlantic wind power anomalies $\left(\Phi_{\mathrm{ww}_{\mathrm{ano}}}\right)$. (b) The seasonal dependence in correlations between monthly interannual Atl3 SST anomalies and tropical Atlantic wind power anomalies $\left(\Phi_{\mathrm{ww}_{\mathrm{ano}}}\right)$. Only correlations significant above the 95 percentile are shown. SST anomalies and wind power anomalies were calculated based on ROMS-TAtl output and a 3-month running mean has been applied to the time series.

also seen to be the dominant component within the anomalous wind power term: $\Phi_{\mathrm{ww}_{\text {ano }}^{x}}>\Phi_{\mathrm{ww}_{\mathrm{ano}}^{y}}$, where $\Phi_{\mathrm{ww}_{\mathrm{ano}}^{x}}=\iint_{z=0} u \tau_{s}^{x} d S-\iint_{z=0} u_{\mathrm{cl}} \tau_{S_{\mathrm{cl}}}^{x} d S$ and $\quad \Phi_{\mathrm{ww}_{\mathrm{ano}}^{y}}=$ $\iint_{z=0} v \tau_{S}^{y} d S-\iint_{z=0} v_{\mathrm{cl}} \tau_{S_{\mathrm{cl}}}^{y} d S$.

The relationship between anomalous meridional wind power and anomalous Atl3 SST is a weak one with the strongest relationship being an insignificant correlation of -0.19 observed at zero lag. This result is not surprising given that zonal wind stress acting on zonal surface currents is seen to be responsible for the majority of work done on the ocean by the wind within the tropical Atlantic (Burls 2010; Burls et al. 2011). The weak relationship between anomalous meridional wind power and anomalous Atl3 SST suggests that variability in subsurface cooling associated with the zonal 
redistribution of warm surface waters in response to large-scale changes in wind forcing (evaluated by APE and zonal wind power fluctuations), rather than locally forced, equatorially asymmetric Ekman pumping anomalies, dominates interannual Atl3 SST variability.
As in Goddard and Philander (2000), wind power, approximated by its zonal component $\left(\Phi_{\mathrm{ww}} \approx\right.$ $\left.\Phi_{\mathrm{ww}^{x}}\right)$, can be decomposed into its climatological $\left(\Phi_{\mathrm{ww}_{\mathrm{cl}}^{x}}=\iint_{z=0} u_{\mathrm{cl}} \tau_{S_{\mathrm{cl}}}^{x} d S\right)$, mean perturbation $\left(\Phi_{\mathrm{ww} \text { ano }}^{m p}=\right.$ $\left.\iint_{z=0} u^{\prime} \tau_{s_{\mathrm{d}}}^{x} d S+\iint_{z=0}^{\mathrm{c}_{\mathrm{cl}}} u_{\mathrm{cl}} \tau_{s}^{x^{\prime}} d S\right)$, and perturbation $\left(\Phi_{\mathrm{ww} \text { ano }}^{p p}=\right.$ $\iint_{z=0} u^{\prime} \tau_{s}^{x^{\prime}} d S$ ) components:

$$
\Phi_{\mathrm{ww}^{x}}=\iint_{z=0} u \tau_{S}^{x} d S=\iint_{z=0}\left(u_{\mathrm{cl}}+u^{\prime}\right)\left(\tau_{\mathrm{cl}^{\mathrm{cl}}}^{x}+\tau_{s}^{x^{\prime}}\right) d S=\iint_{z=0} u_{\mathrm{cl}} \tau_{s_{\mathrm{cl}}}^{x} d S+\iint_{z=0} u^{\prime} \tau_{\mathrm{cl}_{\mathrm{cl}}}^{x} d S+\iint_{z=0} u_{\mathrm{cl}} \tau_{s}^{x^{\prime}} d S+\iint_{z=0} u^{\prime} \tau_{s}^{x^{\prime}} d S .
$$

The mean perturbation component, $\Phi_{\mathrm{ww}_{\mathrm{ann}}}^{m p}$, comprises two terms: $\Phi_{\mathrm{ww} \text { ano }}^{\text {mup }}=\iint_{z=0} u_{\mathrm{cl}} \tau_{s}^{x^{\prime}} d S$, which represents the effects of anomalous zonal wind stress fluctuations acting on climatological surface currents, and $\Phi_{\mathrm{ww}_{\text {ano }}}^{m \tau p u}=$ $\iint_{z=0} u^{\prime} \tau_{S_{\mathrm{cl}}}^{x} d S$, representing the effects of climatological winds acting on anomalous surface current variations. Here $\tau_{s_{\mathrm{cl}}}^{x}$ and $u_{\mathrm{cl}}$ represent the climatological zonal wind stress and surface current values, while $\tau_{s}^{x}$ and $u^{\prime}$ represent interannual perturbations from these climatological fields. Following Eq. (6), anomalous wind power approximated by its zonal component is decomposed into three components:

$$
\Phi_{\mathrm{ww}_{\text {ano }}^{x}}=\Phi_{\mathrm{ww}_{\text {ano }}}^{m u p \tau}+\Phi_{\mathrm{ww}_{\text {ano }}}^{m \tau p u}+\Phi_{\mathrm{ww}_{\text {ano }}}^{p p} .
$$

This decomposition provides us with insight into the dominant mechanism behind tropical Atlantic wind power anomalies. Anomalous tropical Atlantic wind power is the determined primarily by the mean perturbation terms, $\Phi_{\mathrm{ww}_{\text {ano }}}^{m u p \tau}$ and $\Phi_{\mathrm{ww}_{\text {ano }}}^{m \tau p u}$, with fluctuations in the perturbation term, $\Phi_{\mathrm{ww}_{\text {ano }}}^{p p}$, playing a much smaller secondary role (not shown). Here $\Phi_{\mathrm{ww}_{\text {ano }}}^{\text {mup }}=\iint_{z=0} u_{\mathrm{cl}} \tau_{s}^{x^{\prime}} d S$, captures the role of the atmosphere either through stochastic wind forcing or by wind stress fluctuations associated with an anomalous seasonally excited Bjerknes feedback. $\Phi_{\mathrm{ww}_{\text {ano }}}^{m \tau p u}=\iint_{z=0} u^{\prime} \tau_{S_{\mathrm{cl}}}^{x} d S$, captures the role of oceanic adjustment. From an energetics perspective, $\Phi_{\mathrm{ww}_{\mathrm{ano}}}^{m \tau p u}$ captures the effects of the delayed, negative, ocean memory feedback mechanism. In the Pacific this term is seen to be responsible for the transition from El Niño to La Niña (Goddard and Philander 2000). Similarly, results obtained in Burls et al. (2011) suggested that seasonal surface current changes-associated with transients excited by the abrupt seasonal change in zonal wind stress that occurs in May-June (Philander and Pacanowski 1986a; Schouten et al. 2005; Ding et al. 2009)—affect the ability of the wind to do work on the ocean and thus contribute to the decay of the seasonally active Bjerknes feedback in the Atlantic between August and October.

Figure 9 shows the lag-lead relationship between anomalous Atl3 SST and the mean perturbation term
$\Phi_{\mathrm{ww}_{\mathrm{ano}}}^{\text {mup } \tau}$ which represents the effects of anomalous wind forcing on the wind power term (note a 3-month running mean has been applied to each time series). Fluctuations in the mean perturbation term $\Phi_{\mathrm{ww}_{\text {ano }}}^{\text {mup }}$ lead Atl3 SST anomalies by 1 month (Fig. 9a), with a maximum anticorrelation of $r=-0.55$. Note that lag-lead correlations between $\Phi_{\mathrm{ww}_{\text {ano }}}^{\text {mup }}$ and Atl3 SST (Fig. 9a) are more symmetric about zero lag than those between anomalous wind power and Atl3 SST (Fig. 8a).

Figure $9 \mathrm{~b}$ explores whether there is any seasonal dependence in the lag-lead correlation between monthly Atl3 SST anomalies and $\Phi_{\mathrm{ww}_{a n}}^{\text {mup }}$. Correlation values between anomalous Atl3 SST and $\Phi_{\mathrm{ww}_{\text {ano }}}^{\text {mup }}$ peak between April and July with anticorrelation values reaching a maximum at zero lag $(r<-0.75)$. Lag-lead correlations are roughly symmetric during these months. The seasonal dependence in the lag-lead correlation depicted in Fig. 9b, largely resembles that of the seasonal dependence in the correlation between Atl3 SST anomalies and western equatorial Atlantic $\left(5^{\circ} \mathrm{N}-5^{\circ} \mathrm{S}, 40^{\circ}-20^{\circ} \mathrm{W}\right)$ zonal wind stress anomalies (not shown). Therefore, $\Phi_{\mathrm{ww}_{\text {ano }}^{\text {mup }}}$ appears to represents the contribution of anomalous zonal wind stress, associated with interannual variability in the seasonally excited Bjerknes feedback, to wind power anomalies and is responsible for the significant, and roughly symmetric, lag-lead correlations between anomalous At13 SST and wind power are seen in Fig. 8b between April and July. At13 SST anomalies and $\Phi_{\mathrm{ww} \text { ano }}^{\text {mup }}$ typically reinforce one another between April and July as an anomalous evolution of the Bjerknes feedback that is seasonally excited during these months.

Figure 10a shows the lag-lead relationship between the mean perturbation term $\Phi_{\mathrm{ww}_{\text {ano }}}^{m \tau p u}$ and anomalous Atl3 SST (note a 3-month running mean has been applied to each time series). Fluctuations in this term lead Atl3 SST anomalies by 2 months with maximum anticorrelation of $r=-0.36$ (Fig. 10a). Unlike the relationship between $\Phi_{\mathrm{ww}_{a n o}}^{\text {mup }}$ and Atl3 SST seen in Fig. 9a, a positive correlation of 0.35 between $\Phi_{\mathrm{ww}_{2 n}}^{m \tau p u}$ and Atl3

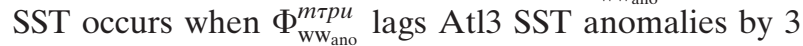
months (Fig. 10a). As seen seasonally in the Atlantic 
(a)

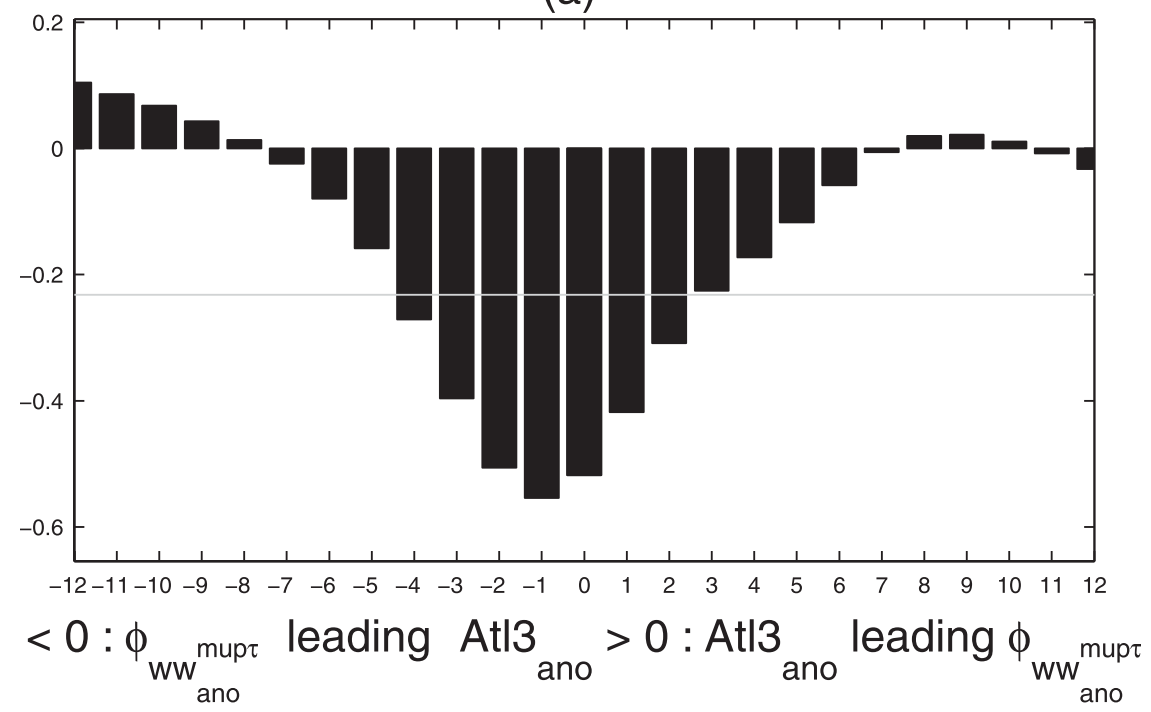

(b) Atl3 $_{\text {ano }}<=>\phi_{\text {ww }_{\text {ano }}^{\text {mupr }}}: 1980-2004$

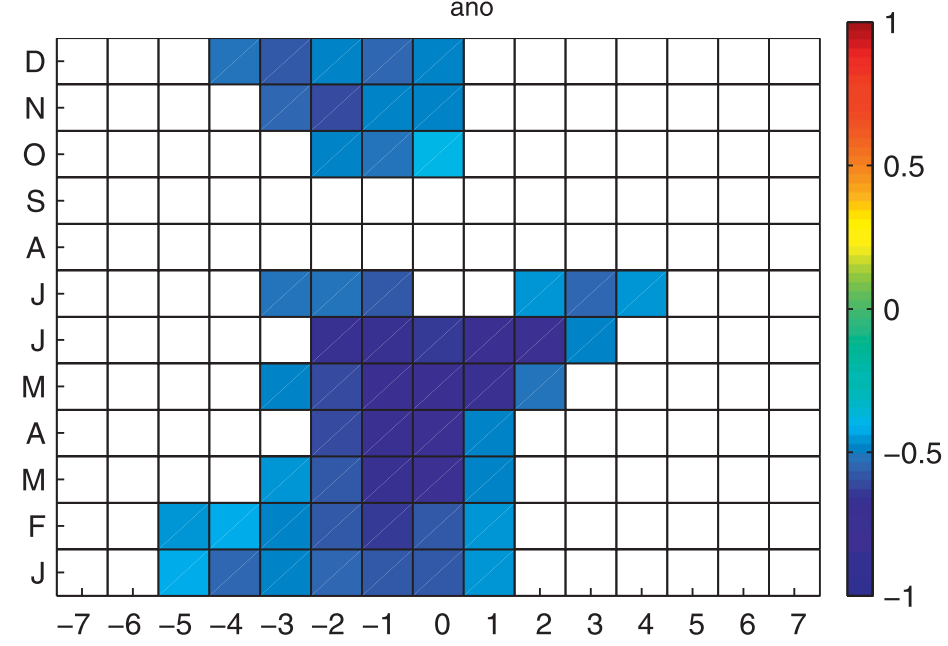

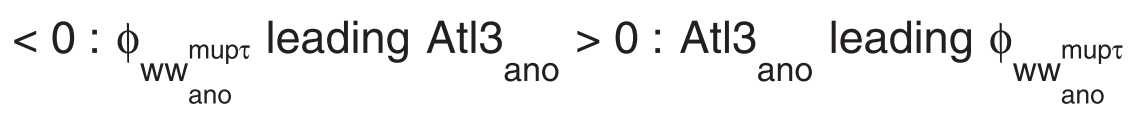

FIG. 9. (a) Time lag correlations between interannual Atl3 SST anomalies and the mean perturbation term $\Phi_{\mathrm{ww}_{\mathrm{ano}}}^{\text {mup }}$. (b) The seasonal dependence in correlations between monthly

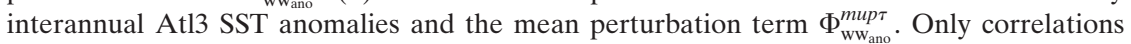

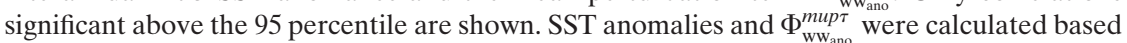
on ROMS-TAtl output and a 3-month running mean has been applied to the time series.

(Burls et al. 2011) and interannually in the Pacific (Goddard and Philander 2000), $\Phi_{\mathrm{ww}_{\text {ano }}}^{m \tau p u}$ represents the effect of transient-induced changes in surface currents on the ability of the wind to do work on the ocean. The anticorrelation of $r=-0.36$ found between $\Phi_{\mathrm{ww}_{\text {ano }}^{m}}^{m \tau p u}$ and Atl3 SST when $\Phi_{\mathrm{ww}_{\text {ano }}}^{m \tau p u}$ leads by 2 months is thought to be the result of the westward equatorial surface current acceleration (deceleration) that accompanies the anomalous Bjerknes feedback associated with cold (warm) At13 SST events. On the other hand, the positive (negative) contribution of $\Phi_{w w_{\text {ano }}}^{m \tau p u}$ to anomalous wind work $\sim 3$ months after a warm (cold) event represents the role of the delayed, negative ocean memory feedback mechanism. This delayed, negative feedback mechanism in the Atlantic operates on much shorter time scales than in the Pacific, where according to 
(a)

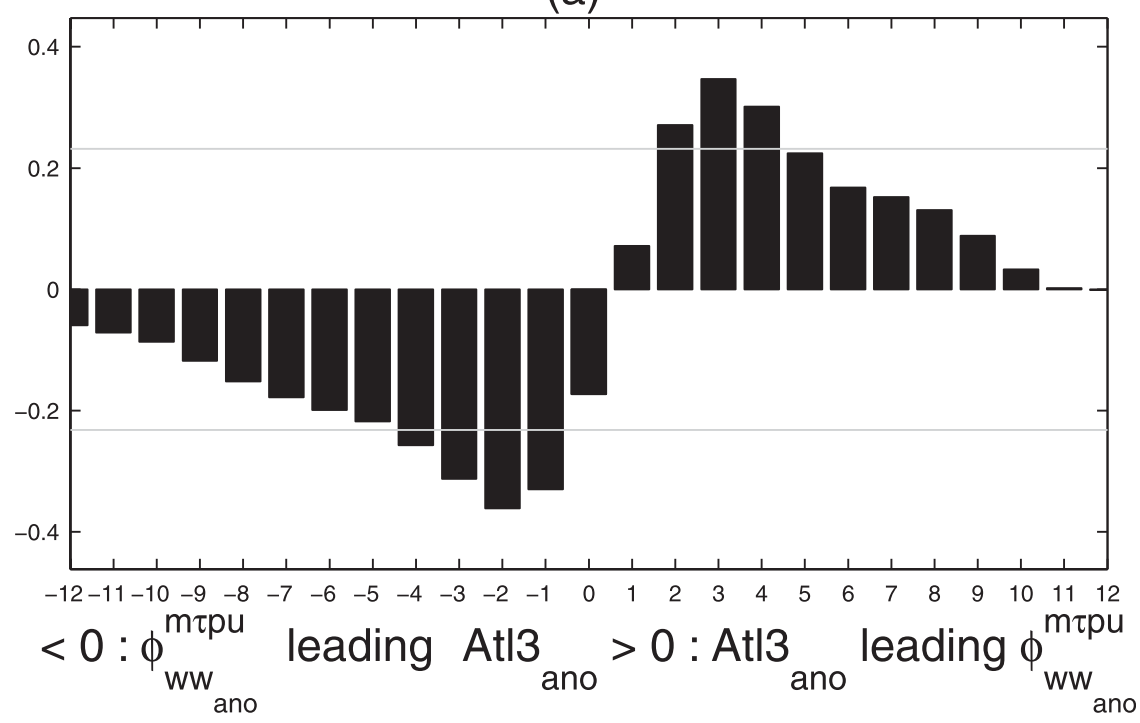

(b) Atl3 $_{\text {ano }}<\phi_{w_{\text {ano }}}^{m \tau p u}: 1980-2004$

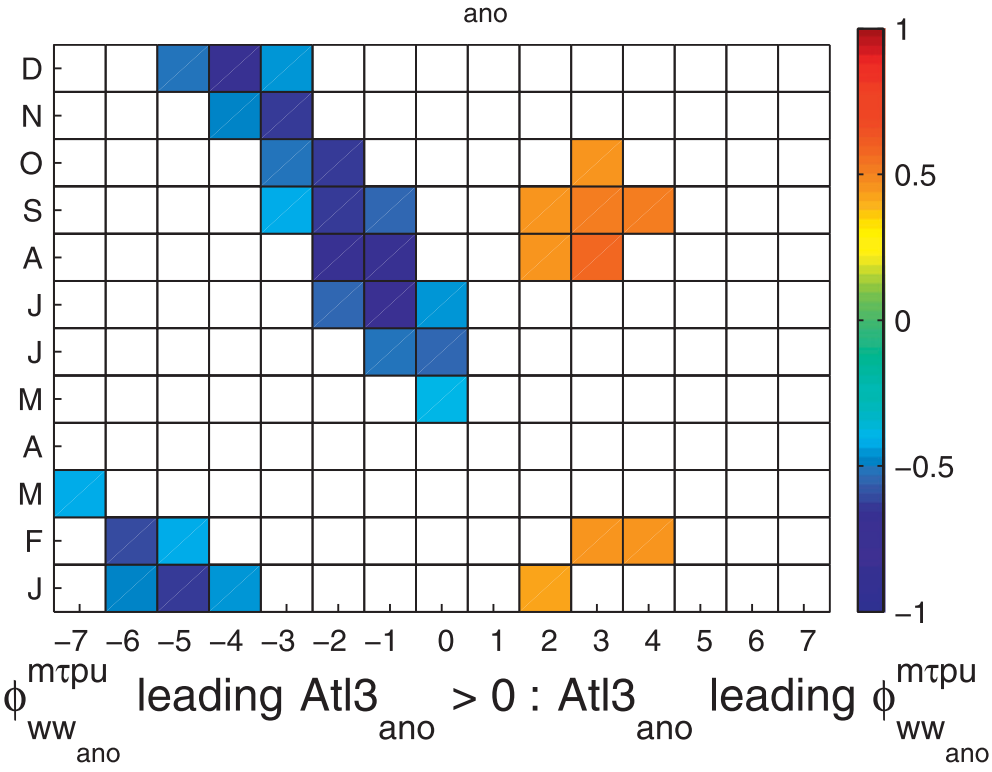

FIG. 10. (a) Time lag correlations between interannual Atl3 SST anomalies and the mean perturbation term $\Phi_{\mathrm{ww}_{\mathrm{ano}}}^{m \tau \text {. }}$. (b) The seasonal dependence in correlations between monthly in-

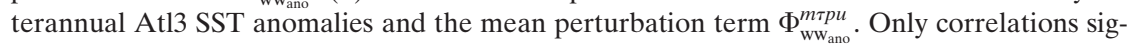
nificant above the 95 percentile are shown. SST anomalies and $\Phi_{\mathrm{ww}_{\text {ano }}}^{m \tau p u}$ were calculated based on ROMS-TAtl output and a 3-month running mean has been applied to the time series.

Goddard and Philander (2000), $\Phi_{\mathrm{ww}_{\text {ano }}}^{m \tau p u}$ contributes positively (negatively) to anomalous wind work 9-12 months after a warm (cold) event.

Figure 10b investigates whether there is any seasonal dependence in the lag-lead correlation between monthly interannual At13 SST anomalies and $\Phi_{\mathrm{ww}_{\mathrm{ano}}}^{m \tau p}$. Anticorrelation values between anomalous At13 SST and $\Phi_{w w_{\text {ano }}}^{m \tau p u}$ peak in July/August with anticorrelation values reaching a maximum $(r<-0.7)$ when $\Phi_{\mathrm{wwano}}^{m \tau p u}$ leads by 1 month. From September to February, the lead grows from 2 months in September to 5 months in January. As mentioned earlier, a possible cause of this growth in the lag-lead relationship between wind work and Atl3 SST anomalies is thought to be the greater persistence in At13 SST anomalies seen during these months. The consistent growth in the lag-lead relationship between wind 
work and Atl3 SST from August to January (Fig. 8b) appears to be primarily associated with the $\Phi_{\mathrm{ww}_{\text {ano }}}^{m \tau p u}$ component of anomalous wind power (Fig. 10b) and to a lesser extent with $\Phi_{\mathrm{ww}_{\text {ano }}}^{m u p \tau}$ (Fig. 9b). This result suggests that the anomalous, central-eastern basin SST variability associated with the November-December zonal mode of Okumura and Xie (2006) is related to wind work anomalies driven primarily by climatological zonal wind stress acting on anomalous surfaced currents during the previous August to September.

Evident in Fig. 10b between August and October are the significant positive correlations between $\Phi_{\mathrm{ww}_{\text {ano }}}^{m \tau p u}$ and Atl3 SST anomalies of $>0.45$ when Atl3 SST leads by $2-4$ months. This feature, also evident in Fig. 8b, is only associated with climatological zonal wind stress fluctuations acting on anomalous surface currents $\left(\Phi_{\mathrm{ww}_{a n o}}^{m \tau p u}\right.$, Fig. 10b) and not with anomalous zonal wind stress fluctuations acting on climatological surface currents $\left(\Phi_{\mathrm{ww}_{\text {ano }} \text {, }}^{\text {mup }}\right.$ Fig. $\left.9 \mathrm{~b}\right)$. Like the positive correlation of 0.35 between $\Phi_{\mathrm{ww}_{a n}}^{m \tau p u}$ and At13 SST shown in Fig. 10a when $\Phi_{\mathrm{ww}_{\mathrm{ano}}}^{m \tau p u}$ lags At13 SST anomalies by 3 months, these positive correlations represent the effects of the ocean memory, negative feedback mechanism. These significant positive correlations between $\Phi_{\mathrm{ww}_{\text {ano }}}^{m \tau p u}$ and Atl3 SST (Fig. 10b) coincide with the time of the year when the seasonally active delayed, negative, ocean memory mechanism, associated with the deceleration of surface currents, acts to decay the seasonally excited Bjerknes feedback mechanism as part of the seasonally active thermocline mode (Burls et al. 2011).

These results offer evidence in support of the hypothesis that anomalous conditions associated with the zonal mode in the tropical Atlantic are typically the result of a modulation of the seasonally active thermocline mode. While an amplified (suppressed) seasonally excited Bjerknes feedback between April and June leads to the growth of anomalous conditions, the seasonally active decay mechanism associated with the delayed deceleration of surface currents between August and October is also amplified (suppressed), hereby leading to the decay of anomalous conditions.

\section{3) INDIVIDUAL EVENTS: AMPLITUdE OR PHASE MODULATIONS OF THE SEASONALLY EXCITED THERMOCLINE MODE}

During some cold and warm event years, the delayed, negative ocean memory feedback mechanism only acts to dissipate the anomalies while, during others, it manages to completely reverse them. This behavior is illustrated when we compare individual cold and warm events, such at the 1992 and 2004 cold events in Fig. 11 and the 1988 and 1991 warm events in Fig. 12.

In the Pacific, the presence of free oscillations associated with the delayed oscillator mode results in an out-of-phase relationship between wind power and APE on interannual time scales (Fedorov 2007). This out-ofphase relationship is due to the fact that APE changes are driven predominately by wind power and wind power displays a dependence on APE via its relationship with surface current anomalies and the ability of the wind to do work on the ocean. This in-quadrature relationship between wind power and APE observed interannually in the Pacific results in a circular trajectory that passes through all four quadrants of a phase diagram with wind power on the horizontal axis and APE on the vertical axis (Fedorov 2007). In Burls et al. (2011), the behavior of the seasonally excited thermocline mode was similarly summarized by a phase diagram between seasonal APE values and the wind power term $\left(\Phi_{\mathrm{ww}_{\mathrm{cl}}}\right)$ as reproduced in gray in Figs. 11e,f and 12e,f. Only between April and September is a circular relationship between APE and the wind power term evident, as it is during these months that the seasonally excited thermocline mode of coupled variability plays an active role in the tropical Atlantic's seasonal cycle.

Figures 11a and 11b compare the 1992 and 2004 values for Atl3 SST and equatorial Atlantic APE against climatological values, Figs. $11 \mathrm{c}$ and $11 \mathrm{~d}$ the relative contribution of mean perturbation terms $\Phi_{\mathrm{ww}_{\text {ano }}}^{m u p}$ and $\Phi_{\mathrm{ww} \text { ano }}^{m \tau p u}$, and Figs. 11e and 11f the tropical Atlantic APE versus wind power phase diagrams. In 1992 anomalously cold At13 SST and high APE conditions during boreal summer are damped between August and December (Figs. 11a,c). However in 2004, anomalously cold Atl3 SST and high APE conditions during boreal summer are reversed in August/September (Figs. 11b,d). When comparing Figs. 11c and 11d, it becomes apparent that the delayed negative feedback associated with $\Phi_{\mathrm{ww}_{\text {ano }}}^{m \tau p u}$ manages to reverse Atl3 SST and equatorial Atlantic APE anomalies in 2004, yet in 1992 anomalously strong winds acting on climatological surface currents $\left(\Phi_{\mathrm{ww}_{\text {ano }}}^{\text {mupq }}\right)$ persist until December 1992; therefore, anomalously weak wind power due to $\Phi_{\mathrm{ww}_{\mathrm{ano}}}^{m \tau u}$ only manages to damp and not reverse anomalous APE conditions. It appears as though the 2004 event was predominantly the result of a shift in the phase of the seasonally excited thermocline mode (Fig. 11f) while the 1992 event was an amplification of the seasonally excited thermocline mode (Fig. 11e).

As with cold events, the delayed, ocean feedback mechanism simply weakens anomalous conditions during some warm event years, while during others it manages to completely reverse anomalous conditions. Figures 12a and 12b compare the 1988 and 1991 values for Atl3 SST and equatorial Atlantic APE against climatological values, Figs. $12 \mathrm{c}$ and $12 \mathrm{~d}$ the relative contribution of mean perturbation terms $\Phi_{\mathrm{ww}_{\text {ano }}}^{m u p \tau}$ and $\Phi_{\mathrm{ww}_{\text {ano }}}^{m \tau p u}$ and Figs. 12e and 12f the tropical Atlantic APE versus 
(a)

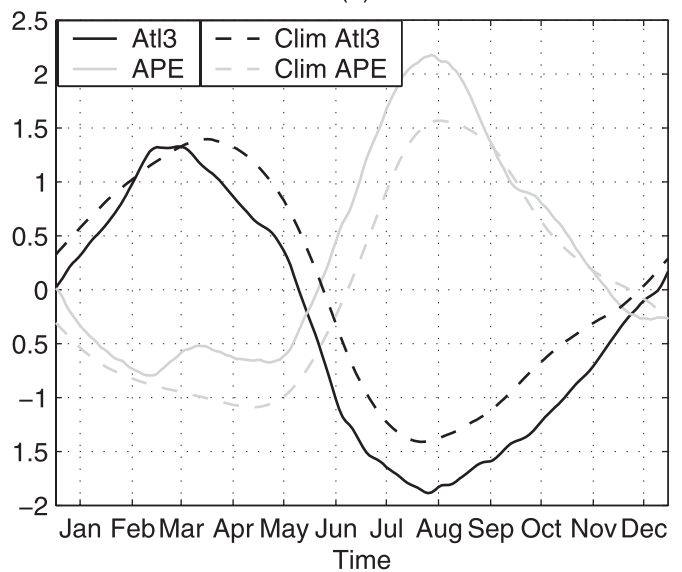

(c)
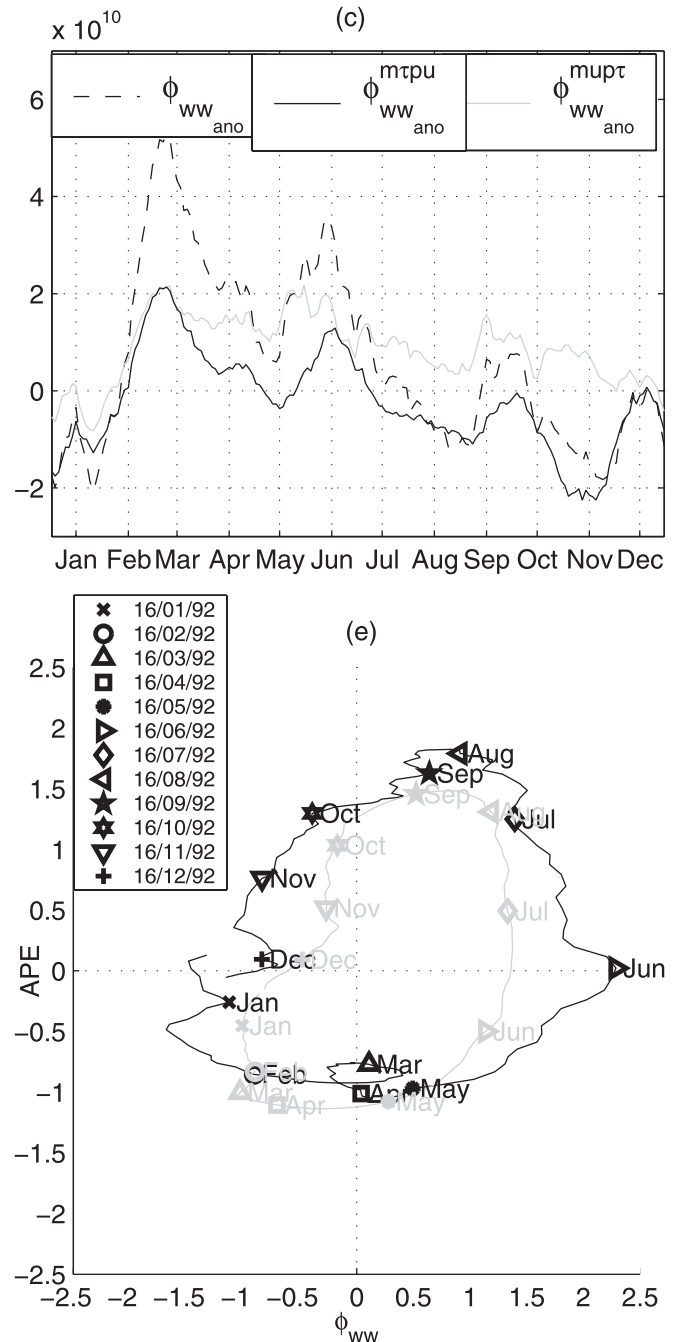

(b)

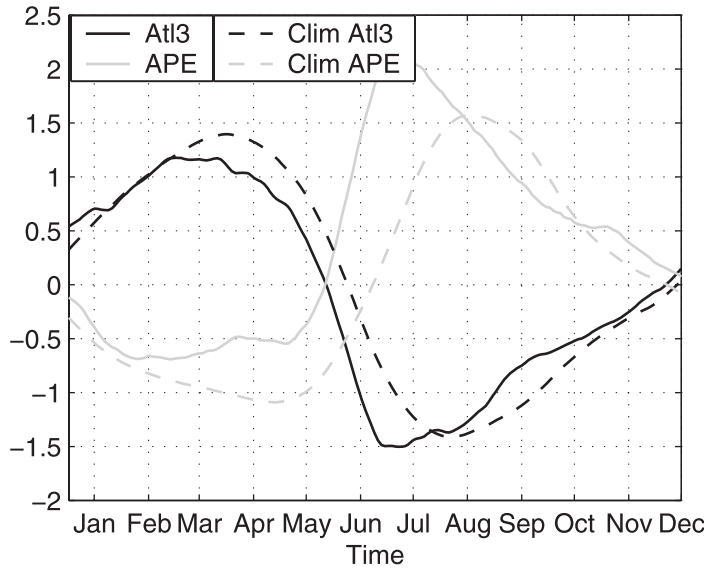

(d)
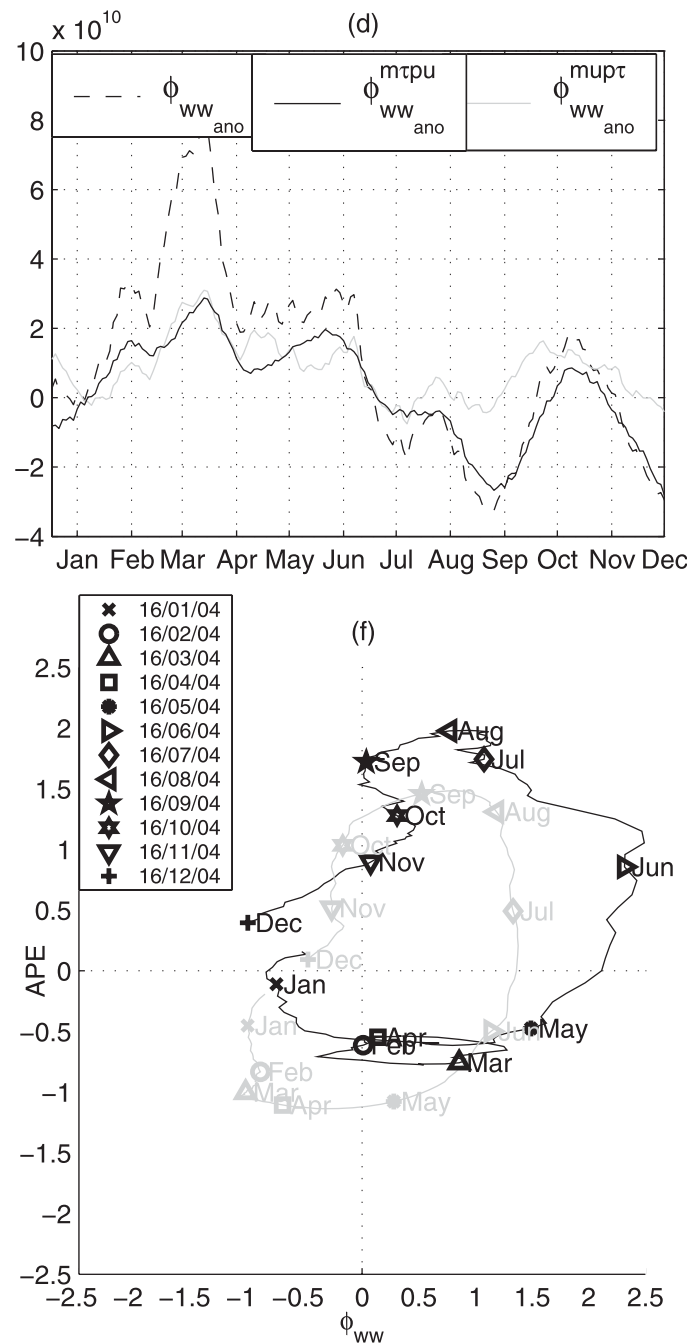

FIG. 11. Total vs climatological normalized values for Atl3 SST and equatorial Atlantic APE in (a) 1992 and (b) 2004. Comparison between wind power anomalies and the mean perturbation terms, $\Phi_{\mathrm{ww}_{a n o}}^{m u p}$ and $\Phi_{\mathrm{ww}_{a n o}}^{m \tau u}$ for (c) 1992 and (d) 2004. Total vs climatological and tropical Atlantic APE vs wind power phase diagrams for (e) 1992 and (f) 2004. The phase diagram of the respective years is shown in black while the climatological phase diagram is shown in gray. These values, calculated based on ROMS-TAtl output, have been normalized and a 14-day running mean has been applied to the time series to smooth out the high-frequency variability. 
(a)

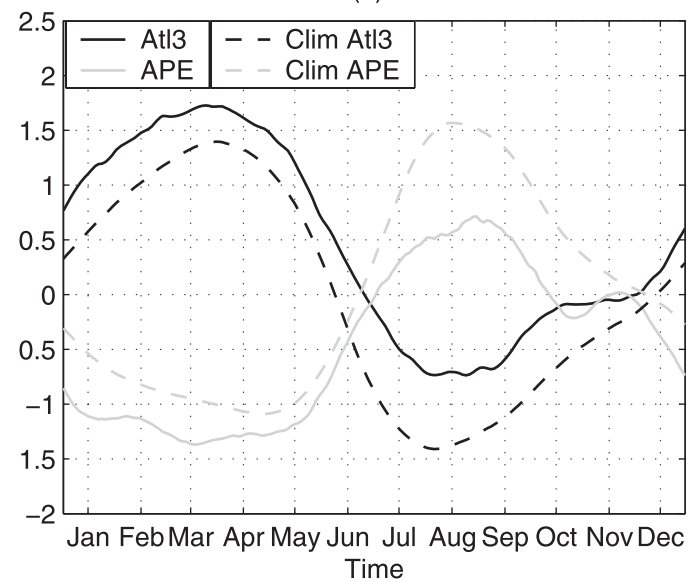

(c)
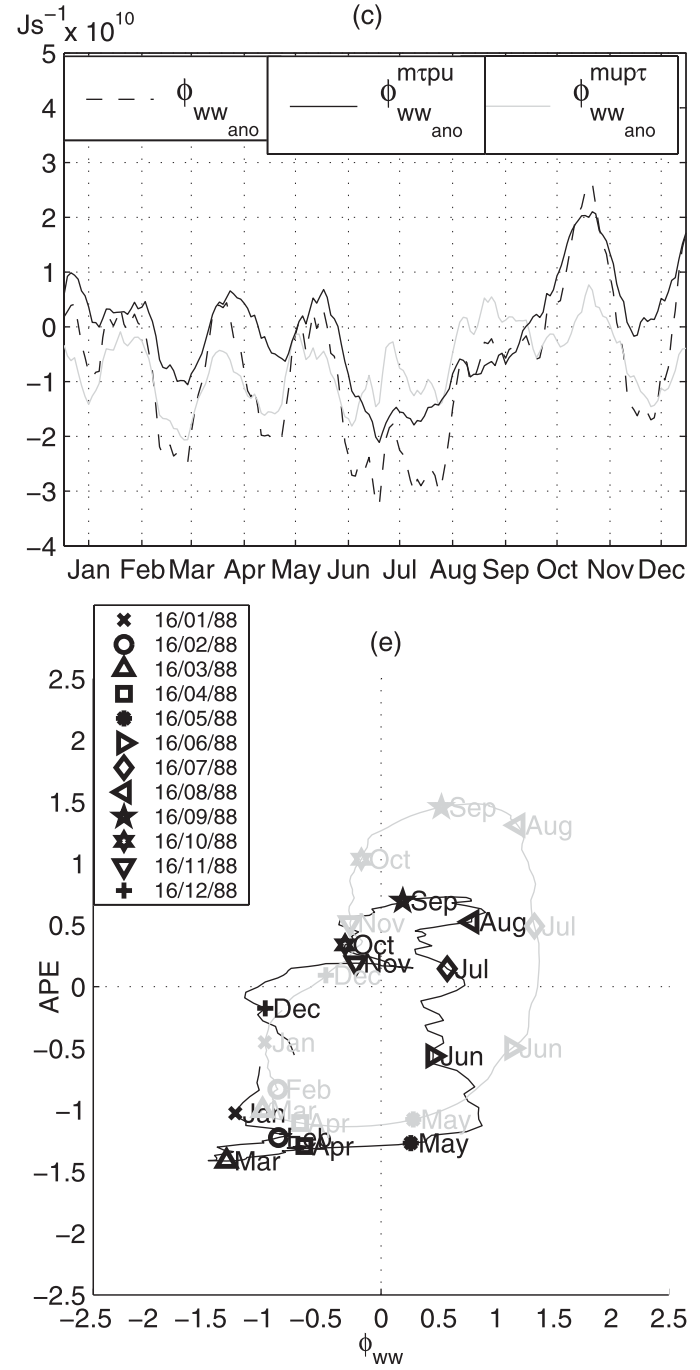

(b)

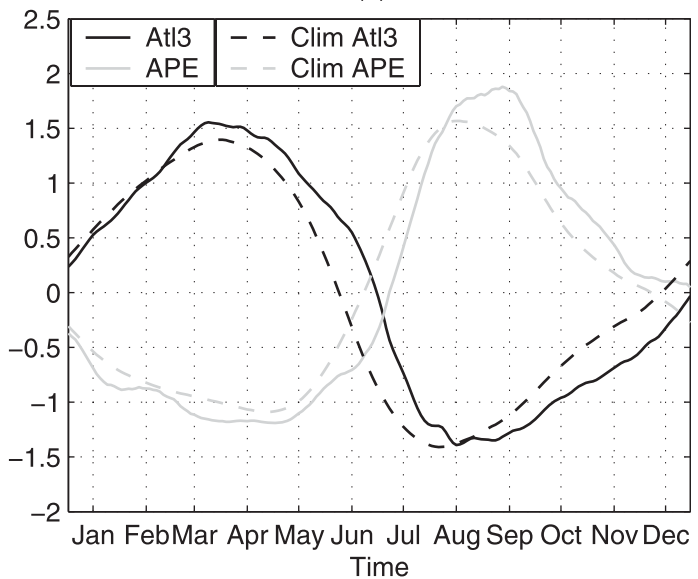

(d)
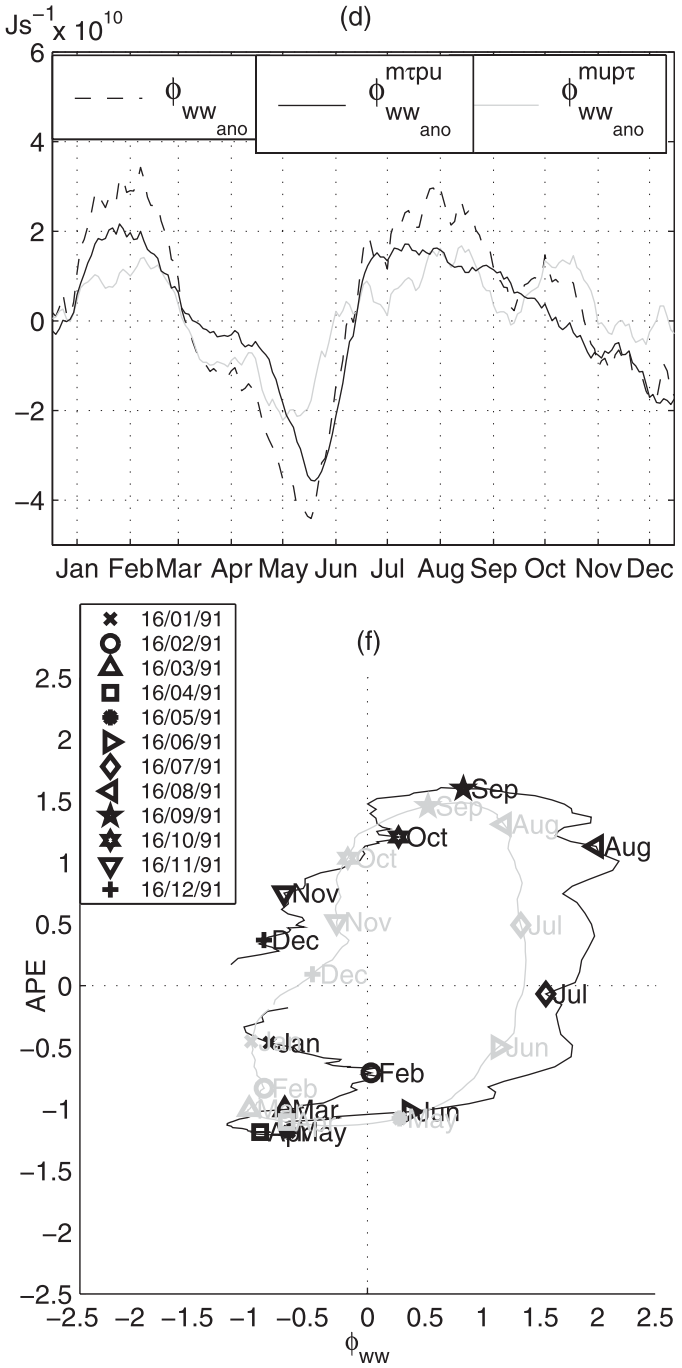

FIG. 12. Total vs climatological values normalized for Atl3 SST and equatorial Atlantic APE in (a) 1988 and (b) 1991 based on ROMS-TAtl output. Comparison between wind power anomalies and the mean perturbation terms, $\Phi_{\mathrm{ww}_{\text {ano }}}^{m \tau p u}$ and $\Phi_{\mathrm{ww}_{\text {ano }}}^{m \tau p u}$ (e) 1988 and (f) 1991. Total vs climatological and tropical Atlantic APE vs wind power phase diagrams for (c) 1988 and (d) 1991. The phase diagram of the respective years is shown in black, while the climatological phase diagram is shown in gray. These normalized values are calculated based on ROMS-TAtl output, and a 14-day running mean has been applied to the time series to smooth out the high-frequency variability. 
wind power phase diagrams. Anomalously warm At13 SST and low APE conditions during the boreal summer of 1988 were damped between September and November (Figs. 12a,c), whereas in 1991 anomalously warm Atl3 SST and low APE conditions between May and July reversed between August and December (Figs. 12b,d). On comparing Figs. 12c and 12d, it becomes apparent that in 1991 the delayed negative feedback associated with $\Phi_{\mathrm{ww}_{\text {ano }}}^{m \tau p u}$ manages to reverse Atl3 SST and equatorial Atlantic APE anomalies, while in 1988 the anomalously weak winds acting on the climatological surface currents, $\Phi_{\mathrm{ww}_{\text {ano }}}^{\text {mup }}$, persist until August. In 1988, anomalously strong

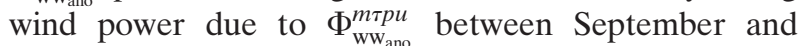
November only manages to damp, and not reverse, anomalous APE conditions. It appears as though the 1991 event was predominantly the result of a shift in the phase of the seasonally excited thermocline mode (Figs. 12b,f), while the 1988 event was the result of a suppression of the seasonally excited thermocline mode (Figs. 12a,e).

\section{c. Interannual modulations of the seasonally excited Bjerknes feedback: Anomalous BPE versus remote atmospheric forcing}

What factors are responsible for interannual modulations of the Bjerknes feedback that is excited seasonally as the cold tongue develops in the Atlantic? One factor might be interannual variability in the seasonal increase in equatorial Atlantic BPE, which appears to precondition the region for the seasonally excited Bjerknes feedback during April-May (Burls et al. 2011). The recent study of Ding et al. (2010) suggests that upperocean heat content anomalies lead central-eastern basin SST anomalies by $4-5$ months.

As revealed by the analysis conducted in section $3 \mathrm{~b}$, anomalous APE changes are not directly influenced by anomalous BPE changes, as fluctuations in the wind power term are seen to be the dominant source of anomalous APE evolution. This finding does not, however, rule out the possibility that anomalously high (low) BPE during April-May could precondition the region by favoring the development of cold (warm) SST anomalies and thus an enhanced (suppressed) seasonally excited Bjerknes feedback. BPE composite anomalies suggest that cold (warm) zonal mode events are typically associated with anomalously high (low) BPE during April-May (not shown, see Burls 2010).

The relationship between equatorial Atlantic APE and BPE anomalies at zero lag is however statistically insignificant with a correlation coefficient of $r=0.23$ $\left(r^{*}=0.29\right)$ between these variables at zero lag, as shown in Fig. 13a. The maximum relationship occurs between equatorial Atlantic APE and BPE anomalies when BPE leads by 1 month $(r=0.34)$. Large BPE changes occur as rapidly as APE changes but less frequently (Fig. 13a). When considering the seasonal dependence within the relationship between anomalous equatorial Atlantic APE and BPE, it is evident that the strongest relationship between these variables occurs between August and December with significant correlations seen between these two variables during this period (Fig. 13b). Correlation values suggest that low (high) BPE anomalies generally lead low (high) APE anomalies by several months between May and October. However, between May and August correlation values are weak, with only patches of significant correlations seen.

The cause of this weak relationship becomes apparent when one considers individual events. While the 1984 , 1988, 1996, 1998, and 1999 warm events all coincided with periods of anomalously low BPE during the preceding months, with anomalous BPE values either approaching or exceeding one standard deviation, for the 1991 event BPE values were exceptionally high (Fig. 13a). Likewise, when one considers cold events, the 1983, 1986, 1992, and 1994 events all corresponded with periods of high BPE, while the 2004 cold event occurred amidst a period when the BPE of the tropical Atlantic was exceptionally low (Fig. 13a).

This analysis suggests that, while anomalous BPE may be one factor contributing to interannual modulations of the seasonally excited Bjerknes feedback, it is not the only factor: the anomalous evolution of the seasonally excited Bjerknes feedback is not consistently associated with anomalous conditions in the background state of the upper tropical Atlantic Ocean. Furthermore, it suggests that variability in the atmospheric component of the coupled system (remote atmospheric forcing or stochasticity of the atmosphere) is just as influential, if not more, as anomalous BPE in driving interannual modulations in the Bjerknes feedback that is seasonally excited in the Atlantic.

It is also worth noting the direct relationship seen between BPE and Atl3 SST anomalies. A significant anticorrelation of $r=-0.49\left(r^{*}=0.29\right)$ exists between equatorial Atlantic BPE and Atl3 SST anomalies at zero lag (Fig. 13a). The maximum anticorrelation $(r=-0.5)$ is found between equatorial Atlantic BPE and Atl3 SST anomalies when the former leads by one month. The relationship between anomalous BPE and SST is strongest between July and October with BPE anomalies leading by $1-2$ months (Fig. 13c). This result suggests that Atl3 SST variability, particularly between July and October exhibits a dependence on BPE anomalies during prior months. Seasonally this period coincides with the months of the year when advection of the density field acts to decrease BPE (Burls et al. 2011) as warm water escape to the north is inhibited (Philander 
(a)

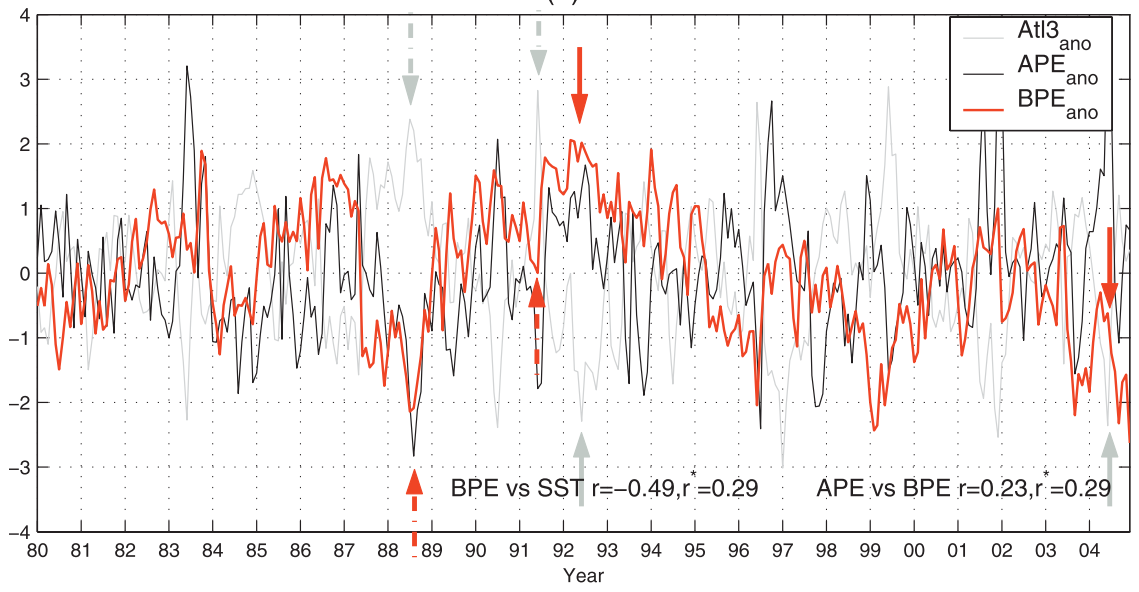

(b) $\mathrm{APE}_{\text {ano }}<=>\mathrm{BPE}_{\text {ano }}: 1980-2004$

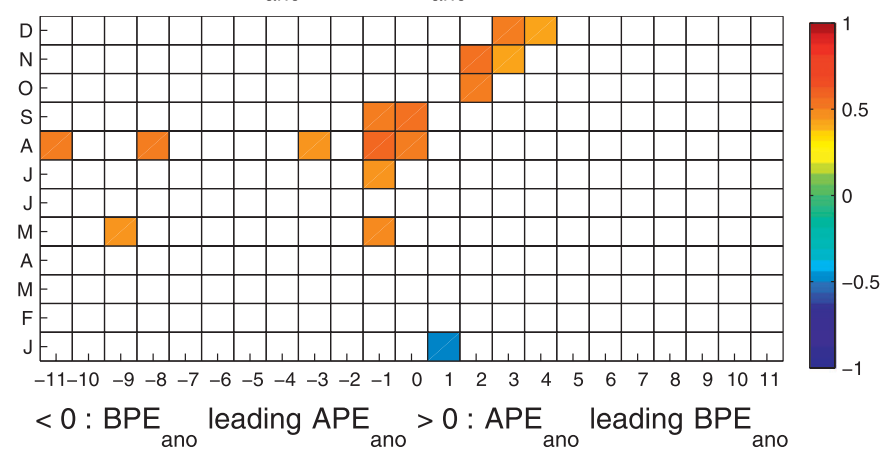

(c) Atl3 <=> BPE $: 1980-2004$

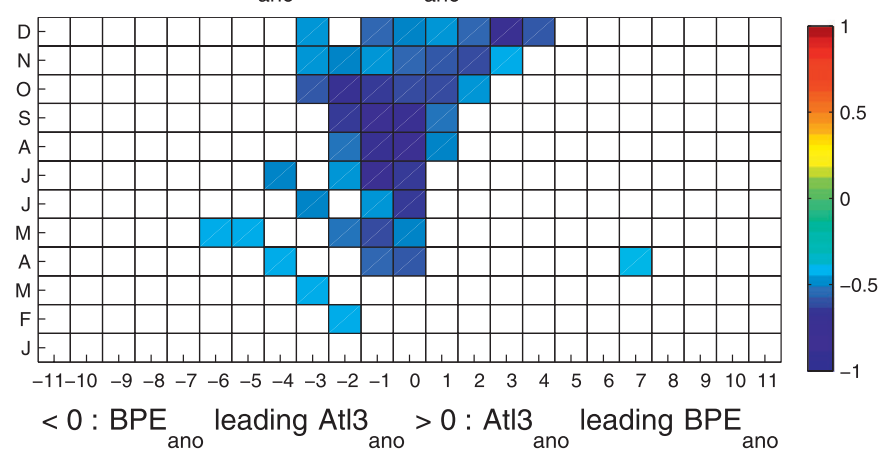

FIG. 13. (a) A comparison between normalized interannual equatorial Atlantic $\left(3^{\circ} \mathrm{S}-3^{\circ} \mathrm{N}\right.$, $\left.60^{\circ} \mathrm{W}-15^{\circ} \mathrm{E}, 0-400 \mathrm{~m}\right) \mathrm{BPE}, \mathrm{APE}$, and Atl3 SST anomalies based on ROMS-TAtl output. The correlation between anomalies $(r)$ is given, together with the required correlation value for significance at the $95 \%$ level taking into account the effective degrees of freedom $\left(r^{*}\right)$. The gray arrows point to Atl3 anomalies during the different cold (solid) and warm (dashed) events, while the red arrows point to BPE anomalies during the different cold (solid) and warm (dashed) events. (b) The seasonal dependence in correlations between equatorial Atlantic APE and BPE anomalies. Only correlations significant above the 95 percentile are shown. (c) The seasonal dependence in correlations between equatorial Atlantic BPE and Atl3 SST anomalies. Only correlations significant above the 95 percentile are shown. 
and Pacanowski 1986b; Lee and Csanady 1999; Bunge and Clarke 2009). Like seasonal BPE fluctuations (Burls 2010; Burls et al. 2011), interannual BPE anomalies are primarily driven by fluctuations in the advection of the density field. These changes in the advection of the density field appear to be related to variability in the warm-water escape process. Anomalously high BPE, typically associated with cold events, is thought to result from anomalously high warm water escape between January and May while anomalous low BPE, typically associated with warm events, is thought to result from anomalously low warm water escape between January and June (Burls 2010). Interannual anomalies in equatorial and tropical Atlantic BPE are strongly related with a maximum correlation coefficient of $r=0.91$ $\left(r^{*}=0.19\right)$ found between them at zero lag.

\section{Conclusions}

The role that ocean dynamical processes play within the zonal mode has been assessed herein from an energetic perspective. Between April and September a circular relationship between APE and the work done on the ocean by the wind suggests that a seasonally excited thermocline mode of coupled variability, driven by a seasonally excited Bjerknes feedback and its subsequent decay, plays an active role in the tropical Atlantic seasonal cycle (Burls et al. 2011). It is shown here that the tropical Atlantic wind power anomalies that give rise to zonal mode events are largely the result of interannual modulations of seasonal wind power fluctuations associated with this seasonally excited thermocline mode. While an amplified (suppressed) seasonally excited Bjerknes feedback between April and July leads to the growth of anomalous conditions, the seasonally active decay mechanism associated with the delayed deceleration of surface currents between August and October is also amplified (suppressed), thereby acting to damp the anomalies. Largely associated with interannual modulations of the delayed, negative feedback response of the seasonally excited thermocline mode between August and October, the delayed, negative feedback mechanism associated with zonal mode events operates on much shorter time scales than that associated with ENSO.

Interannual SST variability in the central-eastern Atlantic associated with anomalous thermocline depth variability therefore appears to be largely due to a modification of the dynamic ocean processes that regulate eastern central basin SST seasonally. In this regard, the zonal mode is unlike ENSO in which this process is an interannual one that is dynamically distinct from the dominant process operating in the tropical
Pacific on seasonal time scales. Seasonal modulations in the timing and intensity of the seasonally excited Bjerknes feedback between April and July are seen as being the primary cause of anomalous SST variability associated with the Atlantic zonal mode. As listed below, this perspective on variability associated with the zonal mode accounts for the differences between ENSO and the Atlantic zonal mode identified in the literature (Zebiak 1993; Chang et al. 2006a).

- First, a weaker and less consistent wind-SST anomaly relationship is observed in the tropical Atlantic compared to the Pacific. Atl3 SST and zonal wind stress anomalies in the western tropical Atlantic appear to only be strongly related to each other between April and August. These SST anomalies manifest within the tropical Atlantic as modulations of the Bjerknes feedback that is seasonally excited during these months. Outside of April-August, Atl3 SST anomalies are more likely to be the result of atmospheric forcing or some other local air-sea interaction process.

- Second, the tropical Atlantic has more high frequency variability within it and larger contributions at seasonal time scales than seems to be found in the tropical Pacific. This difference may be attributed to the coupled variability associated with the Atlantic zonal mode being a modulation of the seasonal cycle. On the other hand, the coupled interactions in the tropical Pacific associated with ENSO are due to a natural mode of variability that operates on interannual time scales.

- Third, the zonal mode and ENSO exhibit very different relationships with the seasonal cycle. SST anomalies associated with ENSO peak in boreal winter, whereas those associated with the Atlantic zonal mode peak in boreal summer. Thus, interpreting the zonal mode as an interannual modulation of the seasonally active thermocline mode in the tropical Atlantic that operates during boreal summer months may account for this difference.

As presented here, this view of the Atlantic zonal mode as a modulation of the seasonally active thermocline mode is consistent with several studies that suggest the zonal mode is damped and noise driven (Latif and Barnett 1995; Nobre et al. 2003; Illig and Dewitte 2006; Kushnir et al. 2006; Keenlyside and Latif 2007). Justification for this view comes from the result that ocean memory, associated with equatorial wave adjustment, is not seen to play a role in sustaining coupled climate oscillations on interannual time scales. This distinct equatorial Atlantic behavior accounts for the limited predictability of interannual fluctuations associated with 
the zonal mode. Furthermore, the results obtained here point to the need for a better understanding of the processes behind the anomalous evolution of the seasonally excited Bjerknes feedback in the equatorial Atlantic between April and July.

Interannual variability in the heat content (BPE) of the tropical Atlantic, driven by that in the warm water escape process in the tropical Atlantic, represents a mechanism that may potentially be responsible for interannual modulations in the seasonally excited Bjerknes feedback. However, the results obtained in this study suggest that the relationship between anomalous BPE and zonal mode events is inconsistent. Thus, atmospheric variability associated with remote atmospheric forcing, with stochasticity of the atmosphere or with the meridional mode, appears to also play an important role in modulating the timing and intensity of the seasonally excited Bjerknes feedback and, hence, in the thermocline mode itself.

The recent work of Lübbecke et al. (2010) suggests that interannual variability in the strength of the South Atlantic subtropical anticyclone plays a role in the development of anomalous central-eastern basin equatorial Atlantic SSTs during boreal summer months. The occurrence of a boreal summer zonal mode event is often linked with the occurrence of a Benguela Niño in the preceding boreal spring months (March-April; Reason et al. 2006; Lübbecke et al. 2010). Lübbecke et al. (2010) refer to combined zonal mode-Benguela Niño warm events as eastern tropical Atlantic Niños that start with a weakening of the southeast trades linked to fluctuations in the strength of the South Atlantic subtropical anticyclone. Similar to Florenchie et al. (2003, 2004), they suggest that the relaxed trades excite eastward equatorial Kelvin waves, which first influence SSTs in the region of the Angola Benguela frontal zone where the thermocline outcrops in March/April and only later in June/July does the seasonal shoaling of the thermocline allow subsurface anomalies to be reflected in the Atl3 SST field. The results of Lübbecke et al. (2010) together with those obtained here suggests that variability in the strength of the South Atlantic subtropical anticyclone is potentially an important source of anomalous tropical Atlantic wind power in the austral summer and boreal spring. This variability could then lead to the anomalous evolution of the seasonally excited Bjerknes feedback as the cold tongue develops during boreal summer months. The relationship between variability in the strength of the South Atlantic subtropical anticyclone and wind work over the tropical Atlantic remains a topic for future research.

The role of stochastic wind forcing in the anomalous evolution of the seasonally excited Bjerknes feedback and hence in zonal mode events is another important factor that deserves further investigation. The results obtained by Marin et al. (2009) (who have compared the development of the cold tongue in the contrasting years of 2005 and 2006) suggest that wind bursts in the Gulf of Guinea may be the cause of interannual variability in the timing of the development of the cold tongue. Differences between the two years were found by Marin et al. to be predominantly the result of a shift in the timing of the development of the cold tongue.

The role of remote ENSO forcing in the development of zonal mode events is yet another key area for future research. The reason for the appearance of anomalously strong trades in the western Atlantic in response to some El Niño events and not others is unclear. Chang et al. (2006b) suggest that the development of anomalously strong trades in response to El Niño events may depend on the nature of SST conditions prior to the El Niño event, stochasticity of the atmosphere, and/or variability in the structure and duration of the atmospheric heating associated with individual El Niño events. Due to the predictability associated with ENSO, an improved understanding of the factors that lead to the appearance of anomalous trades in the western equatorial Atlantic in response to some ENSO events will thus potentially enhance the predictability of zonal mode events.

The decay of meridional mode events in April coincides with the onset period of zonal mode events. Servain et al. (1999) suggested that the zonal and meridional modes are related by the fact that they are both a result of anomalous fluctuations in the trade wind system associated with latitudinal displacements of the ITCZ. The recent results of Foltz and McPhaden (2010a,b) expand on the impact of anomalous fluctuations in the trade wind system associated with meridional mode events during boreal spring. They suggest that zonal wind stress anomalies associated with meridional mode events in boreal spring excite transients, equatorial Kelvin waves, and off-equatorial Rossby waves of the opposite sign. These off-equatorial Rossby waves are then reflected at the western boundary during boreal summer and hence act to damp SST anomalies. In light of these results and the results presented within this paper, we suggest that meridional mode events during the boreal spring could be associated with a shift in the phase of the seasonally excited thermocline mode. For example, anomalously strong zonal wind stress anomalies associated with meridional mode events in boreal spring could promote an early onset of the seasonally excited Bjerknes feedback and, subsequently, an early onset of the seasonally active delayed negative feedback mechanism.

The results obtained in our study suggest that, regardless of how it arises, anomalous wind power over the 
tropical Atlantic could be a potential predictor for zonal mode events. However, because these events result from the modulation of seasonally active coupled processes and not from ones that are independent or operating on interannual time scales, the lead time of this potential predictability appears to be limited to only $1-2$ months.

Acknowledgments. This work emanates from the first author's Ph.D. research and has been supported by resources and funding from the NRF, SANAP, the NRF/ CNRS/French Embassy Doctoral Support Programme, the Centre for High Performance Computing, and the Postgraduate Funding Office at the University of Cape Town, all of which are gratefully acknowledged. The first author would like to thank and acknowledge the reviewers of this paper as well as her Ph.D. examiners for their constructive feedback. [We would like to note that the SODA data of Carton and Giese (2008) was downloaded from http://iridl.ldeo.columbia.edu/SOURCES/. CARTON-GIESE/.SODA/.v2p0p2-4/ and the GODAS data was provided by NOAA/OAR/ESRL PSD, Boulder, Colorado, and downloaded from their website at http:// www.esrl.noaa.gov/psd/.]

\section{APPENDIX}

\section{APE, BPE, and KE Evolution Equations}

In Burls (2010), an evolution equation is derived for APE, as defined by Eq. (1), such that terms are decomposed in a manner relevant to diagnosing equatorial ocean dynamics in an open boundary domain:

$$
\begin{aligned}
\frac{d \mathrm{APE}}{d t} & =\underbrace{\iiint g \tilde{\rho} w d V}_{\Phi_{\text {apk }}}-\underbrace{\oint\left[-g \int_{p^{*}}^{p}\left(z_{*}\left(p^{\prime}\right)-z\right) d p^{\prime}\right] \mathbf{u} \cdot \mathbf{n} d s}_{\Phi_{\text {apa }}}+\underbrace{\iiint g\left(-\alpha \boldsymbol{\nabla} \cdot \gamma_{t}+\beta \boldsymbol{\nabla} \cdot \gamma_{s}-\alpha Q_{t}\right)\left(z-z_{*}\right) d V}_{\Phi_{\text {apd }}} \\
& =\underbrace{\iiint g \tilde{\rho} w d V}_{\Phi_{\text {apk }}}-\underbrace{\oint \mathrm{APE}_{\text {local }} \mathbf{u} \cdot \mathbf{n} d s}_{\Phi_{\text {apa }}}+\underbrace{\iiint g\left(-\alpha \boldsymbol{\nabla} \cdot \gamma_{t}+\beta \boldsymbol{\nabla} \cdot \gamma_{s}-\alpha Q_{t}\right)\left(z-z_{*}\right) d V}_{\Phi_{\text {apd }}}
\end{aligned}
$$

in which $\tilde{\rho}(\mathbf{x}, t)$ represents density perturbations from the reference state density, $\rho^{*}(z, t)=\rho\left(z^{*}, t\right)$, such that $\rho=\rho^{*}(z, t)+\tilde{\rho}(\mathbf{x}, t)$

$$
\gamma_{t}=K_{\mathrm{th}} \frac{\partial T}{\partial x}+K_{\mathrm{th}} \frac{\partial T}{\partial y}+K_{\mathrm{tv}} \frac{\partial T}{\partial z},
$$

where $K_{\text {th }}$ represents the horizontal temperature diffusion coefficient and $K_{\mathrm{tv}}$ the vertical temperature diffusion coefficient;

$$
\gamma_{s}=K_{\mathrm{sh}} \frac{\partial S}{\partial x}+K_{\mathrm{sh}} \frac{\partial S}{\partial y}+K_{\mathrm{sv}} \frac{\partial S}{\partial z}
$$

where $K_{\mathrm{sh}}$ represents the horizontal salinity diffusion coefficient and $K_{\mathrm{sv}}$ represents the vertical salinity diffusion coefficient; and $Q_{t}$ represents subsurface heating due the penetration of the solar radiative flux. The constants $\alpha$ and $\beta$ are the temperature and salinity expansion coefficients, respectively. Here $\mathbf{u}=(u, v, w)$ represents the full three-dimensional velocity field and $-g \int_{\rho^{*}}^{\rho}\left[z_{*}\left(\rho^{\prime}\right)-z\right] d \rho^{\prime}=\mathrm{APE}_{\text {local }}$ is a local definition for APE (Holliday and McIntyre 1981; Molemaker and McWilliams 2010). The derivation of this evolution equation is based on the assumption that a linear equation of state can be used to approximate density, thereby ensuring that the density field is conserved. An evolution equation for the global APE definition given by Eq. (1) has been previously derived (Winters et al. 1995; Huang 1998). However, these studies have focused on somewhat different physical processes and have dealt with closed domains. The above APE evolution equation has been derived such that terms are decomposed in a manner relevant to this paper's focus on equatorial ocean dynamics in an open boundary equatorial domain.

In the form given by Eq. (A1), the temporal evolution of APE within a fluid volume is driven by three terms,

$\Phi_{\text {apk }}$ : The buoyancy power term, which is a reversible exchange term with the KE evolution equation [Eq. (A2)],

$\Phi_{\text {apa }}:$ The advection of local APE across the surfaces of the volume,

$\Phi_{\text {apd }}:$ APE changes due to the combined effects of changes in PE due to mixing within the domain, the rate of change of BPE driven by diapycnal mixing, and changes in APE due to the surface buoyancy flux (Winters et al. 1995; Huang 1998).

To identify the primary physical processes contributing to the buoyancy power term, $\Phi_{\text {apk }}$, which is the reversible exchange term between APE and KE, the balance of terms in the KE evolution equation is evaluated. The KE evolution equation is standard (Winters et al. 1995; Goddard and Philander 2000): 


$$
\begin{aligned}
\frac{d \mathrm{KE}}{d t} & =-\underbrace{\oint\left(\frac{p_{0}}{2} v^{2} \mathbf{u}\right) \cdot \mathbf{n} d s}_{\Phi_{k a}}-\underbrace{\oint(\tilde{p} \mathbf{u}) \cdot \mathbf{n} d s}_{\Phi_{p w}}-\underbrace{\iiint \tilde{\rho} g w d V}_{\Phi_{\mathrm{apk}}}+\underbrace{\iint_{z=0} \mathbf{v} \cdot \tau_{s} d S}_{\Phi_{\mathrm{ww}}} \\
& =-\underbrace{\iiint p_{0}\left[K_{\mathrm{mh}}\left(\frac{\partial \mathbf{v}}{\partial x} \cdot \frac{\partial \mathbf{v}}{\partial x}\right)+K_{\mathrm{mh}}\left(\frac{\partial \mathbf{v}}{\partial y} \cdot \frac{\partial \mathbf{v}}{\partial y}\right)+K_{\mathrm{mv}}\left(\frac{\partial \mathbf{v}}{\partial z} \cdot \frac{\partial \mathbf{v}}{\partial z}\right)\right] d V}_{\Phi_{\mathrm{ss}}}
\end{aligned}
$$

in which $\rho_{o}$ is the constant reference density, $\mathbf{v}=(u, v)$ the horizontal velocity field as vertical velocities do not contribute to KE under the hydrostatic assumption, $K_{\mathrm{mh}}$ is the horizontal viscosity coefficient and $K_{\mathrm{mv}}$ the vertical viscosity coefficient; $\tilde{p}(\mathbf{x}, t)$ represents pressure perturbations from the pressure field $p^{*}(z, t)$ in which all pressure surfaces are level and in hydrostatic balance with $p^{*}(z, t)$, such that $p=p^{*}(z, t)+\tilde{p}(\mathbf{x}, t)$, and $\tau_{s}$ is the surface wind stress.

In this form, the temporal evolution of KE within a fluid volume is driven by five terms,

$\Phi_{\text {apk }}:$ the advection of KE across the surfaces of the volume,

$\Phi_{\text {apa: }}$ : pressure work across the surfaces of the volume (Winters et al. 1995),

$\Phi_{\text {apk }}$ : the buoyancy power term, which is a reversible exchange term with the APE evolution equation [Eq. (A1)],

$\Phi_{\mathrm{ww}}$ : work done by the wind stress acting on surface currents (Goddard and Philander 2000),

$\Phi_{\mathrm{ss}}$ : work done by shear stresses of horizontal flows within the domain (Winters et al. 1995).

The evolution equation for BPE is defined as

$$
\begin{aligned}
\frac{d \mathrm{BPE}}{d t}= & -\underbrace{\iiint g \mathbf{u} \cdot \boldsymbol{\nabla}(-\alpha T+\beta S) z_{*} d V}_{\Phi_{\mathrm{bpa}}} \\
& -\underbrace{\iiint g\left(-\alpha \boldsymbol{\nabla} \cdot \gamma_{t}+\beta \boldsymbol{\nabla} \cdot \gamma_{s}-\alpha Q_{t}\right) z_{*} d V}_{\Phi_{\mathrm{bpd}}} .
\end{aligned}
$$

In this form, the temporal evolution of BPE within a fluid volume is driven by two terms,

$\Phi_{\mathrm{bpa}}$ : BPE changes due to the advection of the density field,

$\Phi_{\text {bpd: }}$ BPE changes due to density diffusion as well as the penetrative solar radiation flux.

\section{REFERENCES}

Behringer, D., and Y. Xue, 2004: Evaluation of the global ocean data assimilation system at NCEP: The Pacific Ocean. Preprints,
Eighth Symp. on Integrated Observing and Assimilation Systems for Atmosphere, Oceans, and Land Surface, Seattle, WA, Amer. Meteor. Soc., 2.3. [Available online at https://ams.confex.com/ ams/pdfpapers/70720.pdf.]

Bjerknes, J., 1969: Atmospheric teleconnections from the equatorial Pacific. Mon. Wea. Rev., 97, 163-172.

Bunge, L., and A. J. Clarke, 2009: Seasonal propagation of sea level along the equator in the Atlantic. J. Phys. Oceanogr., 39, 10691073.

Burls, N. J., 2010: The role of ocean dynamics within tropical Atlantic climate variability. Ph.D. thesis, University of Cape Town, 225 pp.

— C. J. C. Reason, P. Penven, and S. G. Philander, 2011: Similarities between the tropical Atlantic seasonal cycle and ENSO: An energetics perspective. J. Geophys. Res., 116, C11010, doi:10.1029/2011JC007164.

Carton, J. A., and B. Huang, 1994: Warm events in the tropical Atlantic. J. Phys. Oceanogr., 24, 888-903.

— , and B. S. Giese, 2008: A reanalysis of ocean climate using Simple Ocean Data Assimilation (SODA). Mon. Wea. Rev., 136, 2999-3017.

_ G. A. Chepurin, X. Cao, and B. S. Giese, 2000: A Simple Ocean Data Assimilation analysis of the global upper ocean 1950-1995. Part I: Methodology. J. Phys. Oceanogr., 30, 294-309.

Chang, P., and G. Philander, 1994: A coupled ocean-atmosphere instability of relevance to the seasonal cycle. J. Atmos. Sci., 51, 3627-3648.

_ - R. Saravanan, L. Ji, and G. C. Hegerl, 2000: The effect of local sea surface temperatures on atmospheric circulation over the tropical Atlantic sector. J. Climate, 13, 2195-2216.

— pled systems-The role of ocean dynamics. J. Climate, 19, 5122-5174.

— , Y. Fang, R. Saravanan, L. Ji, and H. Seidel, 2006b: The cause of the fragile relationship between the Pacific El Niño and the Atlantic Niño. Nature, 443, 324-328.

Ding, H., N. S. Keenlyside, and M. Latif, 2009: Seasonal cycle in the upper equatorial Atlantic Ocean.J. Geophys. Res., 114, C09016, doi:10.1029/2009JC005418.

,-- , and - 2010: Equatorial Atlantic interannual variability: Role of heat content. J. Geophys. Res., 115, C09020, doi:10.1029/2010JC006304.

Fedorov, A. V., 2007: Net energy dissipation rates in the tropical ocean and ENSO dynamics. J. Climate, 20, 1108-1117.

—, S. L. Harper, S. G. H. Philander, B. Winter, and A. Wittenberg, 2003: How predictable is El Niño? Bull. Amer. Meteor. Soc., 84, 911-919.

Florenchie, P., J. R. E. Lutjeharms, C. J. C. Reason, S. Masson, and M. Rouault, 2003: The source of Benguela Niños in the South Atlantic Ocean. Geophys. Res. Lett., 30, 1505, doi:10.1029/ 2003GL017172.

- C. J. C. Reason, J. R. E. Lutjeharms, M. Rouault, C. Roy, and S. Masson, 2004: Evolution of interannual warm and cold events in the southeast Atlantic Ocean. J. Climate, 17, 2318-2334. 
Foltz, G. R., and M. J. McPhaden, 2010a: Interaction between the Atlantic meridional and Niño modes. Geophys. Res. Lett., 37, L18604, doi:10.1029/2010GL044001.

— the Atlantic cold tongue in 2009. Geophys. Res. Lett., 37, L24605, doi:10.1029/2010GL045522.

Frankignoul, C., and K. Hasselmann, 1977: Stochastic climate models. Part II: Application to SST anomalies and thermocline variability. Tellus, 29, 289-305.

Goddard, L., and S. G. H. Philander, 2000: The energetics of El Niño and La Niña. J. Climate, 13, 1496-1516.

Hastenrath, S., 1984: Interannual variability and annual cycle mechanisms of circulation and climate in the tropical Atlantic sector. Mon. Wea. Rev., 112, 1097-1107.

Hisard, P., 1980: Observation de réponses de type "El Niño" dans l'Atlantique tropical oriental, Golfe de Guinée (Observations of an El Niño-like response in the tropical Atlantic, Gulf of Guinea). Oceanol. Acta, 3, 69-78.

Holliday, D., and M. E. McIntyre, 1981: On potential energy density in an incompressible stratified fluid. J. Fluid Mech., 107, 221-225.

Huang, R. X., 1998: Mixing and available potential energy in a Boussinesq ocean. J. Phys. Oceanogr., 28, 669-678.

Illig, S., and B. Dewitte, 2006: Local coupled equatorial variability versus remote ENSO forcing in an intermediate coupled model of the tropical Atlantic. J. Climate, 19, 5227-5252.

Jackett, D. R., and T. J. McDougall, 1995: Minimal adjustment of hydrostatic profiles to achieve static stability. J. Atmos. Oceanic Technol., 12, 381-389.

Kanamitsu, M., W. Ebisuzaki, J. Woollen, S.-K. Yang, J. J. Hnilo, M. Fiorino, and G. L. Potter, 2002: NCEP-DOE AMIP-II Reanalysis (R-2). Bull. Amer. Meteor. Soc., 83, 1631-1643.

Keenlyside, N. S., and M. Latif, 2007: Understanding equatorial Atlantic interannual variability. J. Climate, 20, 131-142.

Kondo, J., 1975: Air-sea bulk transfer coefficients in diabatic conditions. Bound.-Layer Meteor., 9, 91-112.

Kushnir, Y., W. A. Robinson, P. Chang, and A. W. Robertson, 2006: The physical basis for predicting Atlantic sector seasonalto-interannual climate variability. J. Climate, 19, 5949-5970.

Latif, M., and T. P. Barnett, 1995: Interactions of the tropical oceans. J. Climate, 8, 952-964.

- , and A. Grötzner, 2000: The equatorial Atlantic oscillation and its response to ENSO. Climate Dyn., 16, 213-218.

Lee, S.-K., and G. T. Csanady, 1999: Warm water formation and escape in the upper tropical Atlantic Ocean 2. A numerical model study. J. Geophys. Res., 104 (C12), 29 573-29 590.

Lorenz, E. N., 1955: Available potential energy and the maintenance of the general circulation. Tellus, 7, 157-167.

Lübbecke, J. F., C. W. Böning, N. S. Keenlyside, and S. P. Xie, 2010: On the connection between Benguela and equatorial Atlantic Niños and the role of the South Atlantic anticyclone. J. Geophys. Res., 115, C09015, doi:10.1029/2009JC005964.

Marchesiello, P., J. C. McWilliams, and A. Shchepetkin, 2001: Open boundary conditions for long-term integration of regional oceanic models. Ocean Modell., 3, 1-20.

Marin, F., G. Caniaux, H. Giordani, B. Bourlés, Y. Gouriou, and E. Key, 2009: Why were sea surface temperatures so different in the eastern equatorial Atlantic in June 2005 and 2006? J. Phys. Oceanogr., 39, 1416-1431.

Merle, J., 1980: Seasonal heat budget in the equatorial Atlantic Ocean. J. Phys. Oceanogr., 10, 464-469.

Molemaker, M. J., and J. C. McWilliams, 2010: Local balance and cross-scale flux of available potential energy. J. Fluid Mech., 645, 295-314.
Nobre, P., S. E. Zebiak, and B. P. Kirtman, 2003: Local and remote sources of tropical Atlantic variability as inferred from the results of a hybrid ocean-atmosphere coupled model. Geophys. Res. Lett., 30, 8008, doi:10.1029/2002GL015785.

Okumura, Y., and S.-P. Xie, 2006: Some overlooked features of tropical Atlantic climate leading to a new Niño-like phenomenon. J. Climate, 19, 5859-5874.

Oort, A. H., S. C. Ascher, S. Levitus, and J. P. Peixoto, 1989: New estimates of the available potential energy in the world ocean. J. Geophys. Res., 94 (C3), 3187-3200.

Peter, A., M. L. Henaff, Y. P. Y. du Penhoat, C. Menkes, F. Marin, J. Vialard, G. Caniaux, and A. Lazar, 2006: A model study of the seasonal mixed layer heat budget in the equatorial Atlantic. J. Geophys. Res., 111, C06014, doi:10.1029/2005JC003157.

Philander, S. G. H., and R. C. Pacanowski, 1986a: A model of the seasonal cycle in the tropical Atlantic Ocean. J. Geophys. Res. 91, 14 192-14 206.

- and — 1986b: The mass and heat budgets in a model of the tropical Atlantic. J. Geophys. Res., 91, 14 212-14 220.

Rayner, N. A., D. E. Parker, E. B. Horton, C. K. Folland, L. V. Alexander, D. P. Rowell, E. C. Kent, and A. Kaplan, 2003: Global analyses of sea surface temperature, sea ice, and night marine air temperature since the late nineteenth century. J. Geophys. Res., 108, 4407, doi:10.1029/2002JD002670.

Reason, C., P. Florenchie, M. Rouault, and J. Veitch, 2006: Influences of large scale climate modes and Agulhas system variability on the BCLME region. Benguela-Predicting a Large Marine Ecosystem, V. Shannon et al., Eds., Vol. 14, Large Marine Ecosystems, Elsevier, 223-238.

Reid, R., B. Elliot, and D. Olson, 1981: Available potential energy: A clarification. J. Phys. Oceanogr., 11, 15-29.

Ruiz-Barradas, A., J. A. Carton, and S. Nigam, 2000: Structure of interannual-to-decadal climate variability in the tropical Atlantic sector. J. Climate, 13, 3285-3297.

Schouten, M. W., R. P. Matano, and T. P. Strub, 2005: A description of the seasonal cycle of the equatorial Atlantic from altimeter data. Deep-Sea Res., 52, 477-493.

Servain, J., J. Picaut, and J. Merle, 1982: Evidence of remote forcing in the equatorial Atlantic Ocean. J. Phys. Oceanogr., 12, 457-463.

—_, I. Wainer, J. P. McCreary, and A. Dessier, 1999: Relationship between the equatorial and meridional modes of climatic variability in the tropical Atlantic. Geophys. Res. Lett., 26, 485-488.

Shchepetkin, A., and J. McWilliams, 2005: The regional oceanic modeling system (ROMS): A split-explicit, free-surface, topography-following-coordinate oceanic model. Ocean Modell., 9, 347-404.

Vauclair, F., and Y. du Penhoat, 2001: Interannual variability of the upper layer of the tropical Atlantic Ocean from in situ data between 1979 and 1999. Climate Dyn., 17, 527-546.

,$- \ldots$, and G. Reverdin, 2004: Heat and mass budgets of the warm upper layer of the tropical Atlantic Ocean in 1979-99. J. Phys. Oceanogr., 34, 903-919.

Winters, K. B., P. N. Lombard, J. J. Riley, and E. A. D'Asaro, 1995: Available potential energy and mixing in density-stratified fluids. J. Fluid Mech., 289, 115-128.

Xie, S.-P., and J. A. Carton, 2004: Tropical Atlantic variability: Patterns, mechanisms, and impacts. Earth Climate: The Ocean-Atmosphere Interaction, Geophys. Monogr., Vol. 147, Amer. Geophys. Union, 121-142.

Zebiak, S. E., 1993: Air-sea interaction in the equatorial Atlantic region. J. Climate, 6, 1567-1586. 